\title{
Efficient External Electric Field Manipulated \\ Nonlinear Optical Switches of All-Metal Electride \\ Molecules with Infrared Transparency: Nonbonding \\ Electron Transfer Forms an Excess Electron Lone Pair
}

Hui-Min He, ${ }^{a}$ Ying Li, ${ }^{a}$ Hui Yang, ${ }^{a, b}$ Dan Yu, ${ }^{a} \mathrm{Si}-\mathrm{Yi} \mathrm{Li},{ }^{a} \mathrm{Di} \mathrm{Wu},{ }^{* a}$ Jian-Hua Hou, ${ }^{c}$ Rong-Lin Zhong, ${ }^{a}$ Zhong-Jun Zhou, ${ }^{a}$ Feng-Long Gu, ${ }^{* d}$ Josep M. Luis*e and Zhi-Ru $\mathrm{Li}^{* a}$

${ }^{a}$ Laboratory of Theoretical and Computational Chemistry, Institute of Theoretical Chemistry, Jilin University, Changchun, 130023, China.

${ }^{b}$ School of Chemistry and Chemical Engineering, Shanxi Datong University, Daton 037009,China.

${ }^{c}$ School of Materials Science and Engineering, Changchun University of Science and Technology, Changchun 130022, China.

${ }^{d}$ Center for Computational Quantum Chemistry, South China Normal University, Guangzhou, 510631, China

${ }^{e}$ Institute of Computational Chemistry and Catalysis and Department of Chemistry, University of Girona, Campus de Montilivi, 17071 Girona, Catalonia, Spain. 
ABSTRACT: Focusing on the interesting new concept of all-metal electride, centrosymmetric molecules $\mathrm{e}^{-}+\mathrm{M}^{2+}\left(\mathrm{Ni} @ \mathrm{~Pb}_{12}\right)^{2-} \mathrm{M}^{2+}+\mathrm{e}^{-}(\mathrm{M}=\mathrm{Be}, \mathrm{Mg}$ and $\mathrm{Ca})$ with two anionic excess electrons located at the opposite ends of the molecule are obtained theoretically. These novel molecular all-metal electrides can act as infrared (IR) nonlinear optical (NLO) switches. Whereas the external electric field $(F)$ hardly changes the molecular structure of the all-metal electrides, seriously deforms their excess electron orbitals and average static first hyperpolarizabilities $\left(\beta_{0}{ }^{e}(F)\right)$. For $\mathrm{e}^{-}+\mathrm{Ca}^{2+}\left(\mathrm{Ni} @ \mathrm{~Pb}_{12}\right)^{2-} \mathrm{Ca}^{2+}+\mathrm{e}^{-}$, a small external electric field $F=8 \times 10^{-4}$ au $(0.04 \mathrm{~V} / \AA)$ drives a long-range excess electron transfer from one end of the molecule through the middle all-metal anion cage $\left(\mathrm{Ni} @ \mathrm{~Pb}_{12}\right)^{2-}$ to the other end. This long-range electron transfer is shown by a prominent change of excess electron orbital from double lobes to single lobe, which forms an excess electron lone pair and electronic structure $\mathrm{Ca}^{2+}\left(\mathrm{Ni} @ \mathrm{~Pb}_{12}\right)^{2-} \mathrm{Ca}^{2+}+2 \mathrm{e}^{-}$. Therefore, the small external electric field induces a dramatic $\beta_{0}^{e}(F)$ contrast from 0 (off form) to $2.2 \times 10^{6}$ au (on form) in all-metal electride molecule $\mathrm{Ca}\left(\mathrm{Ni} @ \mathrm{~Pb}_{12}\right) \mathrm{Ca}$. Obviously, such switching is high sensitive. Interestingly, in the switching process, such long-range excess electron transfer does not alter the valence and chemical bond nature. Then, this switching mechanism is a distinct nonbonding evolution named as electronic structure isomerization, which means that such switching has the advantages of being fast and reversible. Besides, these all-metal electride molecules also have rare IR transparent characteristic (1.5-10 $\mu \mathrm{m})$ in NLO electride molecules, and hence are commendable molecular IR NLO switches. Therefore, this work opens a new research field of electric field manipulated IR NLO switches of molecular all-metal electrides. 


\section{INTRODUCTION}

Exploring new chemical species is an eternal theme in chemistry, physics, materials science, pharmacology and so on, due to the new species are the basis and source of unique properties. Electrides are a kind of special ionic solids in which excess electrons serve as anions. ${ }^{1}$ In the positively charged crystalline lattice, anionic electrons in electrides are confined within a interstitial space or cavity. ${ }^{2-9}$ Recently, a new research area of nonlinear optical (NLO) molecules with excess electrons has a rapid development because it has been known that introducing excess electron(s) into a molecule can dramatically increase its static electric first hyperpolarizability $\left(\beta_{0}\right) .{ }^{10-12}$ Especially, many researchers pay attention to the molecular electrides $^{2,4,6-8,13-19}$ containing excess electron anions. Subsequently, a variety of new strategies including the regulation of the push-pull effect, size, shape, and coordination site number of complexants, ${ }^{12}$ as well as spin state of excess electrons and excess electron number, ${ }^{20}$ have been proposed to enhance the NLO response and electronic stability of electride molecules. In previous research works, ${ }^{16-19}$ many electride molecules were constructed by doping alkali atoms into various non-metallic complexants. These electride molecules have large first hyperpolarizabilities $\left(\beta_{0}\right)$ and the working waveband in the visible light range. Last year, a new approach to unambiguously characterize molecular electrides based on the analysis of their electron density was reported. ${ }^{21}$

Recently, all-metal extended Zintl polyanions ${ }^{22-26}$ have been found capable of pushing the valence electrons provided to form excess electrons, which result in the 
generation of a novel kind of compounds. Interesting examples include: $\left[\left(\mathrm{Ca}^{2+}\right)_{5}(\mathrm{Ag}-\right.$ $\left.\mathrm{Ag})^{4-}\left(\mathrm{Ag}^{2-}\right)\right]+4 \mathrm{e}^{-}$and $\left[\left(\mathrm{Ca}^{2+}\right)_{5}(\mathrm{Au}-\mathrm{Au})^{4-}\left(\mathrm{Au}^{2-}\right)\right]+4 \mathrm{e}^{-}$with dimer polyanion ${ }^{22}$, and magnetic superatoms $\mathrm{A}_{n} \mathrm{~V}(\mathrm{~A}=\mathrm{Na}$, and $\mathrm{Cs} ; n=6$ to 12$)$ with monomer polyanion. ${ }^{27}$ This novel kind of species not only has an all-metal composition features but also has electride characteristic with excess electron anions. Hence, we proposed the new conception, "all-metal electride", to define the novel intermetallic compounds. To explore NLO properties of all-metal electrides, the CuAg@Ca7M (M = Be, Mg and Ca) molecules have been constructed and researched in detail theoretically. ${ }^{28}$ It was showed that $\left[\left(\mathrm{Ca}^{2+}\right)_{7}(\mathrm{CuAgMg})^{4-}\right]+10 \mathrm{e}^{-}$has large $\beta_{0}$ of $1.4 \times 10^{4}$ au. These all-metal electride molecules not only manifest large $\beta_{0}$, but also have rare infrared (IR) transparent characteristic (1.3-6 $\mu \mathrm{m})$ among NLO electride molecules, and hence are unique IR NLO molecules.

Nonlinear optical (NLO) switches are special molecules which can commute between two or more forms, and thereby shows large contrasts in their NLO properties. As a result, such molecules have attracted great interest in recent years because of their high potential application in signal processing, data storage, sensing, and molecular devices. ${ }^{29-32}$ Castet and co-workers have put forward that the molecular NLO switches may be mainly classified into four categories: light irradiation (photo-isomerization), ${ }^{33-39} \mathrm{pH}$ variation, $^{40-42}$ redox reaction, ${ }^{43-47}$ and ion recognition. ${ }^{48-50}$ For instance, Champagne et al. ${ }^{32}$ have indicated that the ion recognition switches may be utilized as selective ion sensors, which could be acted as a vigorous and multi-usage detection tool. 
On the other hand, the effect of an external electric field on a substance is a wide research area, and has attractive prospects in spintronics, ${ }^{51-53}$ superconductivity, ${ }^{54,55}$ nano material, ${ }^{56,57}$ NLO properties, ${ }^{58,59}$ and so on. For NLO switches, electric-field-driven switching has been noticed by researchers. Nakano and colleagues have shown that switching on an external electric field generates a considerable increase of the second hyperpolarizability in a polyaromatic diradicaloid. ${ }^{60}$ For centrosymmetric aromatic benzene molecule, we have also shown that a large external electric field generate a high contrast in static first hyperpolarizability (from $\beta_{0}{ }^{e}(0)=0$ to $\beta_{0}{ }^{e}(F)=3.9 \times 10^{5}$ au) due to the breaking of the centrosymmetry of its electron density. ${ }^{61}$ For the heterobicycles bisboronate, ${ }^{62}$ the electric field induced molecular NLO switch have also been researched. Very recently, an organic molecular electride $\mathrm{e}^{-\cdots} \mathrm{K}(1)^{+\cdots}$ calix[4]pyrrole $\cdots \mathrm{K}(2)^{+\cdots} \mathrm{e}^{-}$having two excess electrons with singlet diradical characteristic has been reported as an electric field manipulated molecular NLO switch. ${ }^{63}$

The above-mentioned NLO switches involve organic molecules, organometallic complexes and organic electride molecules. However, all-metal electride molecule with IR-transparent characteristic as new NLO switch has not been reported. As all-metal molecular electride not only possesses easily driven excess electrons by external electric field, but also show high IR NLO contrast, all-metal molecular electride may be regarded as potential IR NLO switch. Therefore, we have designed and investigated by means of the computational chemistry three all-metal electride 
molecules $\mathrm{M}\left(\mathrm{Ni} @ \mathrm{~Pb}_{12}\right) \mathrm{M}(\mathrm{M}=\mathrm{Be}, \mathrm{Mg}$ and $\mathrm{Ca})$ as novel external electric field driven NLO switches.

\section{COMPUTUTIONAL METHODS}

The exact-exchange-incorporated PBE0 is the one of most appropriate functionals in the study of the electronic structure of molecules containing transition metals. ${ }^{64-70}$ For molecular structure and property calculations, the choice of a suitable basis sets is another significant concern. For systems with heavy metals, Los Alamos pseudopotential and double-zeta type basis set, LANL2DZ, ${ }^{71-73}$ for the transition metals and Pople-type basis sets for the other atoms have been shown to be competent basis set combination. ${ }^{74}$

In this article, optimized geometric structures with all real frequencies under various external electric field strengths from 0 to $40 \times 10^{-4}$ au were obtained for all-metal electride molecules $\mathrm{M}\left(\mathrm{Ni} @ \mathrm{~Pb}_{12}\right) \mathrm{M}(\mathrm{M}=\mathrm{Be}, \mathrm{Mg}$ and $\mathrm{Ca})$ at the PBE0 level with the LANL2DZ pseudopotential and basis sets for $\mathrm{Ni}$ and $\mathrm{Pb}$ and the 6-311++G(2d) basis set for Be, Mg and Ca. The vertical ionization potentials (VIP) of these molecules under the external electric fields were obtained at the same level. The VIP is defined as follows: ${ }^{18}$

$$
\mathrm{VIP}=E\left[\mathrm{M}^{+}\right]-E[\mathrm{M}]
$$

Where, the energies $E\left[\mathrm{M}^{+}\right]$and $E[\mathrm{M}]$ are calculated at the optimum geometry of the neutral molecule. We used unrestricted orbitals for the ionic molecule and restricted orbitals for the neutral molecule.

The singlet diradical character ${ }^{60,75}\left(y_{0}\right)$ is computed at UHF/6-311++G(2d) level. 
And the electronic absorption spectrum is calculated at CIS/LANL2DZ/6-311+G(3df) level including 300 states.

For accurately calculating the static electronic first hyperpolarizabilities, the research of the optimum basis set ${ }^{76-81}$ show the crucial significance of introducing diffuse basis functions. Furthermore, the basis sets effects have been discussed in detail for electrides, ${ }^{82}$ and singlet diradical systems. ${ }^{83}$ The electronic and vibrational contributions to the first hyperpolarizabilities of these all-metal molecular electride within an external electric fields were calculated by the finite field approach based on the calculations using second-order Møller-Plesset (MP2) method $^{84,85}$ in conjunction with the LANL2DZ pseudopotential and basis set for $\mathrm{Ni}$ and $\mathrm{Pb}$ and the 6-311+G(3df) basis set for $\mathrm{Be}, \mathrm{Mg}$ and $\mathrm{Ca}$. The average static first hyperpolarizability $\left(\beta_{0}\right)$ is noted as follows:

$$
\beta_{0}=\left(\beta_{x}^{2}+\beta_{y}^{2}+\beta_{z}^{2}\right)^{1 / 2}
$$

where

$$
\beta_{i}=\frac{3}{5}\left(\beta_{i i i}+\beta_{i j j}+\beta_{i k k}\right) ; i, j, k=x, y, z
$$

The electronic contributions to first hyperpolarizabilities were evaluated numerically based on the differentiation of the analytic dipole moment $\left(\mu^{\rho}\right)$ and electronic polarizability $\left(\alpha^{\alpha}\right)$ respect to the electric field. The comparison between the $\beta^{e}$ values obtained from the differentiation of $\mu^{e}$ and $\alpha^{e}$ allows us to check that the numerical errors of the $\beta^{e}$ values were negligible.

The vibrational contributions to the first hyperpolarizability was computed using the Bishop-Hasan-Kirtman approach. ${ }^{86}$ According to Bishop and coworkers, if we 
denote the equilibrium molecular geometry with an external electric field $F$ present by $\mathrm{R}_{F}$ and without the field present, by $\mathrm{R}_{0}$, then we may define:

$$
\left(\Delta \mu_{i}^{e}\right)_{R_{0}}=\mu_{i}^{e}\left(\mathrm{~F}, R_{0}\right)-\mu_{i}^{e}\left(0, R_{0}\right)
$$

and

$$
\left(\Delta \mu_{i}^{e}\right)_{R_{F}}
$$

$=\mu_{i}^{e}\left(\mathrm{~F}, R_{F}\right)$

$-\mu_{i}^{e}\left(0, R_{0}\right)$

The electronic contribution to the (hyper)polarizabilities can be derived from the expansion of Eq. (1). But the expansion of Eq. (2) leads to the definition of the electronic and also the vibrational (nuclear relaxation) contributions to the (hyper)polarizabilities,

$$
\mu_{i}^{e}\left(F, \mathrm{R}_{F}\right)=a_{1} F_{j}+1 / 2 \mathrm{~b}_{1} F_{j} F_{k}+1 / 6 \mathrm{~g}_{1} F_{j} F_{k} F_{l}+\cdots \cdot
$$

where

$$
\begin{aligned}
& a_{1}=\alpha_{i j}^{e}(0 ; 0)+\alpha_{i j}^{n r}(0 ; 0)+\cdots \\
& b_{1}=\beta_{i j k}^{e}(0 ; 0,0)+\beta_{i j k}^{n r}(0 ; 0,0)+\cdots \\
& g_{1}=\gamma_{i j k l}^{e}(0 ; 0,0,0)+\gamma_{i j k l}^{n r}(0 ; 0,0,0)+\cdots
\end{aligned}
$$

$P^{e}$ and $P^{n r}$ denotes the electronic and vibrational (nuclear relaxation) contributions to the (hyper)polarizabilities. ${ }^{87}$ The same approach is used in this paper to compute the $\beta_{z z Z}^{e}(F)$ and $\beta_{z z Z}^{n r}(F)$ contributions of a molecule within a permanent static electric field. In order to check the reliability of the numerical values of $\beta_{z Z Z}^{n r}(F)$, we compared the results obtained using at least two different sets of two field values in the second derivative finite-field difference formula. The optimal 8 / 38 
applied electric field strengths were between \pm 0.0010 au and \pm 0.0015 au for Be(Ni@Pb 12$)$ Be; between \pm 0.0001 au and \pm 0.0003 au for $\mathrm{Mg}\left(\mathrm{Ni} @ \mathrm{~Pb}_{12}\right) \mathrm{Mg}$; and between \pm 0.0002 au and \pm 0.0006 au for $\mathrm{Ca}\left(\mathrm{Ni} @ \mathrm{~Pb}_{12}\right) \mathrm{Ca}$..

All of the calculations were performed by using the Gaussian09 program package. ${ }^{88}$ Molecular orbitals were generated with the GaussView program. ${ }^{89}$

\section{RESULTS AND DISCUSSION}

\subsection{Equilibrium Geometries}

We sandwiched the all-metal cage Ni@Pb12 with two alkaline-earth metal M atoms to design a centrosymmetric all-metal electride NLO switch molecule, where the former behaves as potential electron-pushing complexant and the latter acts as excess electron source. The unusual all-metal cage Ni@Pb12 with high symmetry $\left(I_{h}\right)$ is further stabilized by the interaction between the $\mathrm{Pb}_{12}$ cage and the encapsulated $\mathrm{Ni}$ atom. ${ }^{90}$ In the $\mathrm{M}\left(\mathrm{Ni} @ \mathrm{~Pb}_{12}\right) \mathrm{M}$ molecule, all-metal cage Ni@Pb 12 firstly obtains two electrons from the two $\mathrm{M}$ atoms and becomes an electron-pushing complexant, namely, all-metal anion cage $\left(\mathrm{Ni} @ \mathrm{~Pb}_{12}\right)^{2-}$. Then it pushes the rest of the two valence electrons of the two $\mathrm{M}$ atoms to form two excess electrons located at the opposite sides of the molecule. Thus, the $\mathrm{M}\left(\mathrm{Ni} @ \mathrm{~Pb}_{12}\right) \mathrm{M}$ molecule is an all-metal electride molecule containing two excess electrons. The structural sketch maps of the all-metal electride molecules $\mathrm{M}\left(\mathrm{Ni} @ \mathrm{~Pb}_{12}\right) \mathrm{M}(\mathrm{M}=\mathrm{Be}, \mathrm{Mg}$ and $\mathrm{Ca})$ are illustrated in Figure 1. Besides, the geometry-optimized minimum structures of these molecules are also achieved under different external electric fields.

Table 1 presents the evolution of some structural parameters of electride 
molecules $\mathrm{M}\left(\mathrm{Ni} @ \mathrm{~Pb}_{12}\right) \mathrm{M}(\mathrm{M}=\mathrm{Be}, \mathrm{Mg}$ and $\mathrm{Ca})$ caused by increasing external electric field strength: the M1-Ni distance slightly decreases, while the Ni-M2 distance slightly increases (see Table 1). The sum of two distances, the M1-M2 distance, also slightly increases $(<1 \%)$ when the strength of the electric field increases. As the influence of external electric field on molecular structures is small, used external electric fields hardly change the molecular structures. The external electric fields also do not alter the valence and chemical bond nature in the molecular structure due to the dependencies between the geometrical structure and chemical bond nature.

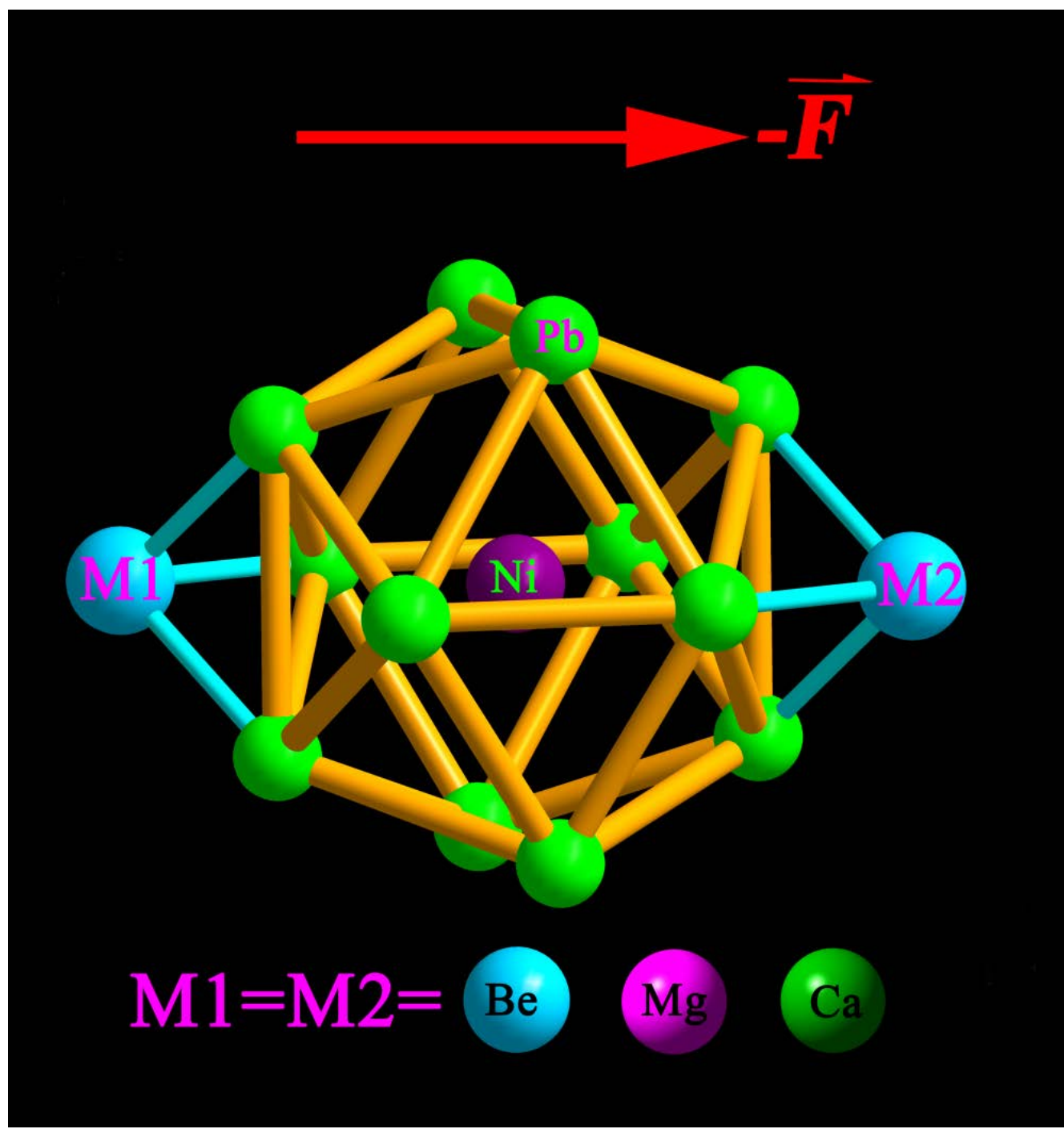

Figure 1 Optimized structures of all-metal electride molecules $\mathrm{M}\left(\mathrm{Ni} @ \mathrm{~Pb}_{12}\right) \mathrm{M}(\mathrm{M}=\mathrm{Be}, \mathrm{Mg}$ and 10 / 38 
Ca) with $\mathrm{M}$ atom labels.

Table 1 Evolution of selected structural parameters of all-metal electride molecules $\mathrm{M}\left(\mathrm{Ni} @ \mathrm{~Pb}_{12}\right) \mathrm{M}(\mathrm{M}=\mathrm{Be}, \mathrm{Mg}$ and $\mathrm{Ca})$ with increasing external electric field strength $F$.

\begin{tabular}{|c|c|c|c|c|c|c|c|c|c|c|c|c|}
\hline & $F / 10^{-4}$ au & 0 & 4 & 5 & 8 & 10 & 15 & 20 & 25 & 30 & 35 & 40 \\
\hline \multirow[t]{3}{*}{ Be(Ni@Pb $\left.{ }_{12}\right) \mathrm{Be}$} & Be1-Ni & 4.028 & 4.014 & 4.008 & 3.979 & 3.967 & 3.938 & 3.912 & 3.883 & 3.860 & 3.838 & 3.820 \\
\hline & Ni-Be2 & 4.020 & 4.035 & 4.041 & 4.074 & 4.089 & 4.128 & 4.167 & 4.209 & 4.251 & 4.294 & 4.336 \\
\hline & Be1-Be2 & 8.048 & 8.049 & 8.049 & 8.053 & 8.056 & 8.066 & 8.079 & 8.092 & 8.110 & 8.132 & 8.156 \\
\hline \multirow[t]{3}{*}{ Mg(Ni@Pb12)Mg } & Mg1-Ni & 4.637 & 4.395 & 4.376 & 4.335 & 4.315 & 4.282 & 4.261 & 4.249 & 4.243 & 4.242 & 4.244 \\
\hline & Ni-Mg2 & 4.637 & 4.922 & 4.949 & 5.015 & 5.051 & 5.121 & 5.177 & 5.220 & 5.260 & 5.293 & 5.320 \\
\hline & Mg1-Mg2 & 9.274 & 9.317 & 9.325 & 9.350 & 9.366 & 9.403 & 9.437 & 9.470 & 9.503 & 9.535 & 9.564 \\
\hline \multirow[t]{3}{*}{$\mathrm{Ca}\left(\mathrm{Ni} @ \mathrm{~Pb}_{12}\right) \mathrm{Ca}$} & Ca1-Ni & 5.031 & 4.982 & 4.970 & 4.935 & 4.913 & 4.864 & 4.825 & 4.796 & 4.776 & 4.765 & 4.761 \\
\hline & Ni-Ca2 & 5.031 & 5.083 & 5.097 & 5.137 & 5.164 & 5.228 & 5.288 & 5.340 & 5.386 & 5.422 & 5.449 \\
\hline & Ca1-Ca2 & 10.062 & 10.065 & 10.067 & 10.072 & 10.077 & 10.092 & 10.113 & 10.136 & 10.162 & 10.187 & 10.210 \\
\hline
\end{tabular}

\subsection{Molecular Stabilities}

For these all-metal electride molecules, the electronic stability is important in view of the existence of loosely-bound excess electrons. The electronic stability of a molecule may be characterized by its first vertical ionization potential (VIP) value. From Table 2, it can be seen that field-free VIP values of $\mathrm{M}\left(\mathrm{Ni} @ \mathrm{~Pb}_{12}\right) \mathrm{M}(\mathrm{M}=\mathrm{Be}$, $\mathrm{Mg}$ and $\mathrm{Ca}$ ) increase in the order $\mathrm{Ca}<\mathrm{Be}<\mathrm{Mg}$. The VIP values of these molecules are slightly larger than the reported values of inorganic and organic electride molecules, ${ }^{16,91,92}$ but smaller than the large value $(7.78 \mathrm{eV})$ of the electride molecule with the excess electron protected inside the $\mathrm{C}_{36} \mathrm{~F}_{36}$ cage. ${ }^{93}$ Hence, these all-metal electride molecules exhibit moderate electronic stability among investigated electride molecules. Note that the VIP values of these all-metal electride molecules only slightly vary with increasing external electric field (see Table 2), indicating that the influence of external electric field on electronic stability is small. 
It is well-known that the gap between HOMO (the highest occupied molecular orbital) and LUMO (the lowest unoccupied molecular orbital) is another useful

Table 2 First vertical ionization potentials (VIP, in eV), energy values of HOMOs $\left(\varepsilon_{\text {номо, in }}\right.$ $\mathrm{eV}$ ), and HOMO-LUMO Gaps (H-L Gap, in eV).

\begin{tabular}{lccccccccccc}
\hline $\mathrm{F} / 10^{-4} \mathrm{au}$ & 0 & 4 & 5 & 8 & 10 & 15 & 20 & 25 & 30 & 35 & 40 \\
\hline $\mathrm{VIP}$ & & & & & & & & & & & \\
$\mathrm{Be}\left(\mathrm{Ni} @ \mathrm{~Pb}_{12}\right) \mathrm{Be}$ & 5.10 & 5.10 & 5.10 & 5.11 & 5.15 & 5.23 & 5.14 & 5.38 & 5.14 & 5.08 & 5.08 \\
$\mathrm{Mg}\left(\mathrm{Ni} @ \mathrm{~Pb}_{12}\right) \mathrm{Mg}$ & 5.56 & 5.08 & 5.29 & 5.09 & 5.26 & 5.24 & 5.01 & 5.43 & 5.06 & 5.65 & 5.45 \\
$\mathrm{Ca}\left(\mathrm{Ni} @ \mathrm{~Pb}_{12}\right) \mathrm{Ca}$ & 4.47 & 4.46 & 4.46 & 4.48 & 4.45 & 4.44 & 4.45 & 4.47 & 4.50 & 4.55 & 4.60 \\
$\varepsilon_{\text {Hомо }}$ & & & & & & & & & & & \\
$\mathrm{Be}\left(\mathrm{Ni} @ \mathrm{~Pb}_{12}\right) \mathrm{Be}$ & -4.26 & -4.26 & -4.26 & -4.27 & -4.27 & -4.28 & -4.29 & -4.30 & -4.32 & -4.34 & -4.37 \\
$\mathrm{Mg}\left(\mathrm{Ni} @ \mathrm{~Pb}_{12}\right) \mathrm{Mg}$ & -4.33 & -4.36 & -4.37 & -4.38 & -4.40 & -4.42 & -4.45 & -4.48 & -4.52 & -4.55 & -4.58 \\
$\mathrm{Ca}\left(\mathrm{Ni} @ \mathrm{~Pb}_{12}\right) \mathrm{Ca}$ & -3.65 & -3.65 & -3.65 & -3.65 & -3.66 & -3.67 & -3.69 & -3.71 & -3.74 & -3.78 & -3.82 \\
$\mathrm{H}-\mathrm{L} \mathrm{Gap}(\mathrm{eV})$ & & & & & & & & & & & \\
$\mathrm{Be}\left(\mathrm{Ni} @ \mathrm{~Pb}_{12}\right) \mathrm{Be}$ & 1.40 & 1.40 & 1.40 & 1.40 & 1.40 & 1.40 & 1.41 & 1.42 & 1.43 & 1.44 & 1.45 \\
$\mathrm{Mg}(\mathrm{Ni} @ \mathrm{~Pb}$ & \\
$\mathrm{Ca}\left(\mathrm{Ni} @ \mathrm{Mg} \mathrm{P}_{12}\right) \mathrm{Ca}$ & 1.24 & 1.26 & 1.26 & 1.28 & 1.29 & 1.31 & 1.33 & 1.36 & 1.38 & 1.41 & 1.43 \\
& 0.96 & 0.96 & 0.96 & 0.97 & 0.98 & 1.00 & 1.02 & 1.06 & 1.10 & 1.14 & 1.19 \\
\hline
\end{tabular}

quantity for examining the molecular chemical stability. A large gap value reflects a high chemical stability. Table 2 lists the HOMO-LUMO (H-L) gaps of these all-metal electride molecules $\mathrm{M}\left(\mathrm{Ni} @ \mathrm{~Pb}_{12}\right) \mathrm{M}(\mathrm{M}=\mathrm{Be}, \mathrm{Mg}$ and $\mathrm{Ca})$. These values, which are relatively smaller than those of organic electride, ${ }^{91,92,94,95}$ decrease in the order Be $>$ $\mathrm{Mg}>\mathrm{Ca}$. However, HOMO-LUMO gap values of M(Ni@Pb$\left.{ }_{12}\right) \mathrm{M}(\mathrm{M}=\mathrm{Be}, \mathrm{Mg}$ and Ca) are comparable or larger than those of the all-metal clusters with interstitial La ion. ${ }^{96}$ Therefore, these studied all-metal electride molecules have the chemical stabilities close to those of some organic electrides and all-metal clusters.

\subsection{Changes of Excess Electron Orbitals Caused by Increasing External Electric}

Field 
As far as we know, molecular orbital (MO) changes caused by an external electric fields are rarely reported, ${ }^{61,63}$ let alone field-induced evolution of excess electron

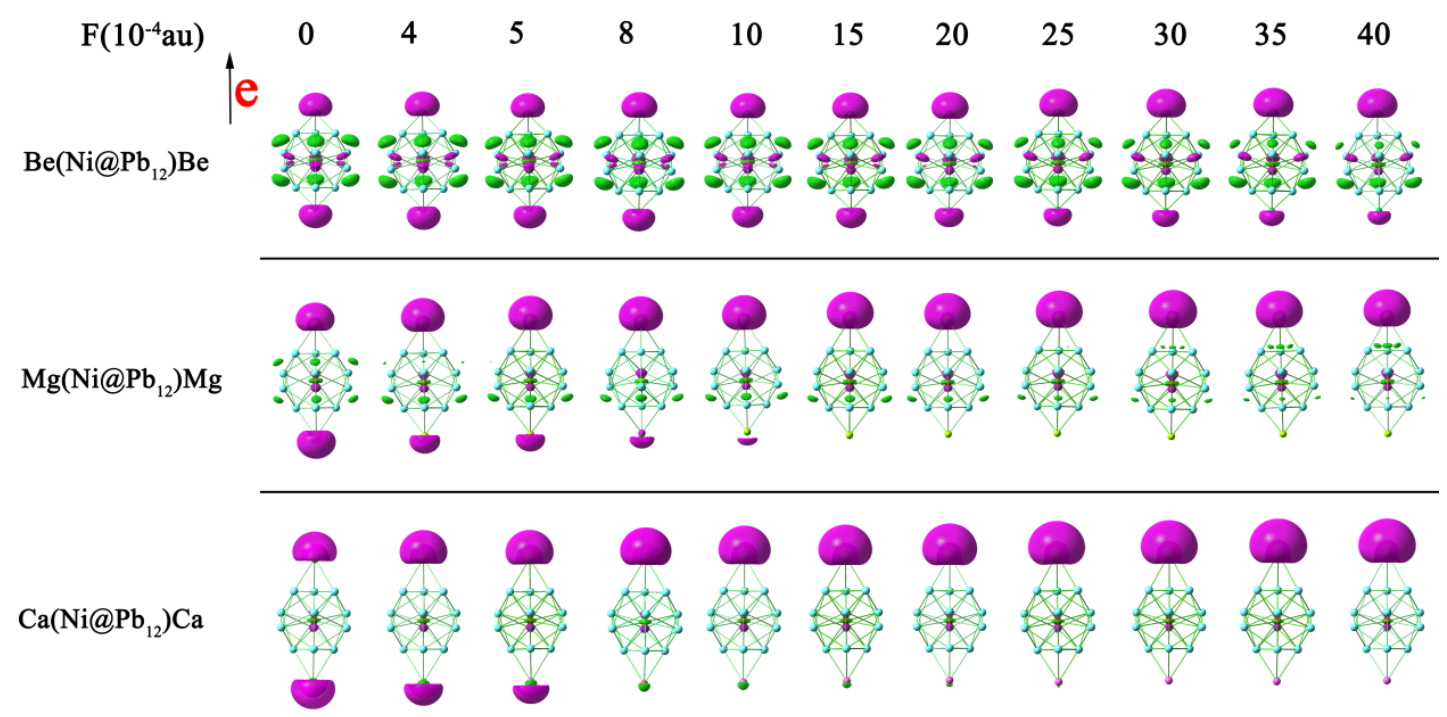

Figure 2 Evolutions of HOMOs of $\mathrm{M}\left(\mathrm{Ni} @ \mathrm{~Pb}_{12}\right) \mathrm{M}(\mathrm{M}=\mathrm{Be}, \mathrm{Mg}$ and $\mathrm{Ca})$ with increasing external electric field strength.

orbitals of an all-metal electride molecule. Interestingly, the HOMOs of the $\mathrm{M}\left(\mathrm{Ni} @ \mathrm{~Pb}_{12}\right) \mathrm{M}(\mathrm{M}=\mathrm{Be}, \mathrm{Mg}$ and $\mathrm{Ca})$ species are all occupied by two excess electrons, as is shown in Figure 2. In Figure 2 we also present the modifications of HOMO provoked by the increasing external electric field strength.

The HOMO orbital of $\mathrm{M}\left(\mathrm{Ni} @ \mathrm{~Pb}_{12}\right) \mathrm{M}$ involves two delocalized electrons from two $\mathrm{M}$ atoms, which exist in the form of loosely bound excess electrons. Without the influence of external electric field, they occupy two hemispherical orbital lobes located at two opposite ends of the molecule. Therefore, the all-metal molecule $\mathrm{M}\left(\mathrm{Ni} @ \mathrm{~Pb}_{12}\right) \mathrm{M}$ looks like an electride molecule with a salt-like electronic structure $\mathrm{e}^{-}+\left(\mathrm{M}^{2+}\right)\left(\mathrm{Ni} @ \mathrm{~Pb}_{12}\right)^{2-}\left(\mathrm{M}^{2+}\right)+\mathrm{e}^{-}$. Within an external electric field parallel to the $\mathrm{M}-\mathrm{M}$ axis, one of the HOMO electrons is partly transferred from the lower lobe to the upper 
lobe, leading to asymmetric HOMO orbitals of $\mathrm{M}\left(\mathrm{Ni} @ \mathrm{~Pb}_{12}\right) \mathrm{M}(\mathrm{M}=\mathrm{Be}, \mathrm{Mg}$ and $\mathrm{Ca})$. As the external electric field further strengthens, the lower lobe tends to totally merge into the upper one, and then a long-range excess electron transfer occurs through the

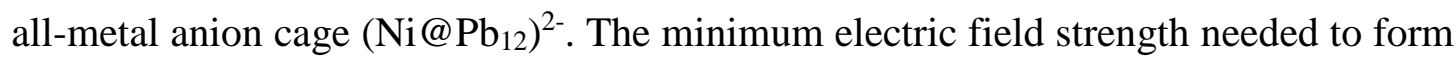
a single lobe orbital of excess electron lone pair is named as single lobe orbital electric field $\left(F_{s}\right)$. Obviously, the $F_{s}$ values of the $\mathrm{M}\left(\mathrm{Ni} @ \mathrm{~Pb}_{12}\right) \mathrm{M}$ molecules vary depending on the atomic number of alkaline-earth metal atom $\mathrm{M}$.

For the HOMO of $\mathrm{Be}\left(\mathrm{Ni} @ \mathrm{~Pb}_{12}\right) \mathrm{Be}$, even at the largest computed strength of the electric field ( $F=40 \times 10^{-4}$ au), there is still a two-lobe orbital with a large and a small lobe. That is, the $F_{s}$ of $\mathrm{Be}\left(\mathrm{Ni} @ \mathrm{~Pb}_{12}\right) \mathrm{Be}$ is out of the studied electric field range. For the HOMO of $\mathrm{Mg}\left(\mathrm{Ni} @ \mathrm{~Pb}_{12}\right) \mathrm{Mg}$, the $F_{s}$ value is located at $15 \times 10^{-4} \mathrm{au}$. And for $\mathrm{Ca}\left(\mathrm{Ni} @ \mathrm{~Pb}_{12}\right) \mathrm{Ca}$, similarly, a single lobe HOMO with two excess electron lone pair appears at $8 \times 10^{-4}$ au $\left(F_{s}\right)$. Then, at higher electric fields than $F_{s}$, the electronic structure of $\mathrm{Mg}\left(\mathrm{Ni} @ \mathrm{~Pb}_{12}\right) \mathrm{Mg}\left(\mathrm{Ca}\left(\mathrm{Ni} @ \mathrm{~Pb}_{12}\right) \mathrm{Ca}\right)$ can also be described as salt-like $\mathrm{Mg}^{2+}\left(\mathrm{Ni} @ \mathrm{~Pb}_{12}\right)^{2-} \mathrm{Mg}^{2+}+2 \mathrm{e}^{-}\left(\mathrm{Ca}^{2+}\left(\mathrm{Ni} @ \mathrm{~Pb}_{12}\right)^{2-} \mathrm{Ca}^{2+}+2 \mathrm{e}^{-}\right)$. The field-induced evolution of excess electron orbitals can be considered the origin of field-induced evolutions of electronic molecular structure and properties. From Table 2, we can see that when external electric field strength increases, the HOMO orbital energies monotonically decrease. Therefore, the external electric field decreases the molecular reductant strength (the ability of donating electron to the species with large electronegativity) of these all-metal molecular electrides. 
As previously reported, the electride molecule $\mathrm{e}^{-} \cdots \mathrm{K}(1)^{+} \cdots$ calix[4]pyrrole $\cdots \mathrm{K}(2)^{+} \cdots \mathrm{e}^{-}$, which has two excess electrons separated by organic molecule calix[4]pyrrole, has dual characteristics of electride and singlet diradical. $^{63}$ In this paper, the all-metal electride molecules $\mathrm{e}^{-+}\left(\mathrm{M}^{2+}\right)\left(\mathrm{Ni} @ \mathrm{~Pb}_{12}\right)^{2-}\left(\mathrm{M}^{2+}\right)+\mathrm{e}^{-}$also has two excess electrons located at opposite ends of the molecule. Then, are these three all-metal electride $\mathrm{M}\left(\mathrm{Ni} @ \mathrm{~Pb}_{12}\right) \mathrm{M}$ unusual singlet diradical molecules?

A singlet molecule having two weakly interacting electrons with similar energy may be an open-shell singlet diradical system. In the molecular orbital (MO) picture, they are also represented as systems with two nearly degenerate bonding and antibonding MOs. ${ }^{97}$ However, the singlet diradical characteristic of an all-metal electrides molecule has not been discussed yet.

Figure 3 shows the HOMO of two isolated electride molecules $\mathrm{e}^{-} \cdots \mathrm{Ca}^{+} \mathrm{F} \cdots \mathrm{FCa}^{+} \cdots \mathrm{e}^{-}$and the HOMO of an organic electride molecule $\mathrm{e}^{-\cdots} \mathrm{Li}^{+} \mathrm{NH}_{2} \mathrm{PhNH}_{2} \mathrm{Li}^{+} \cdots \mathrm{e}^{-}$with two separated isolated excess electrons.

(a) $\mathrm{e}^{-\cdots} \mathrm{Ca}^{+} \mathrm{F} \cdots \mathrm{FCa}^{+} \cdots \mathrm{e}^{-}$
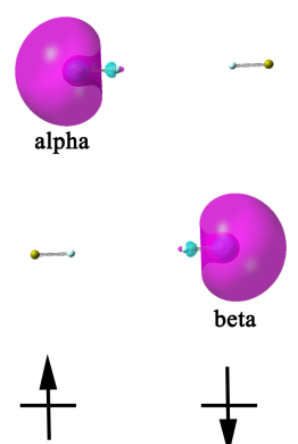

Singlet Diradical

Two Electride (b) $\mathrm{e}^{-\cdots} \mathrm{Li}^{+} \mathrm{NH}_{2} \mathrm{PhNH}_{2} \mathrm{Li}^{+} \cdots \mathrm{e}$
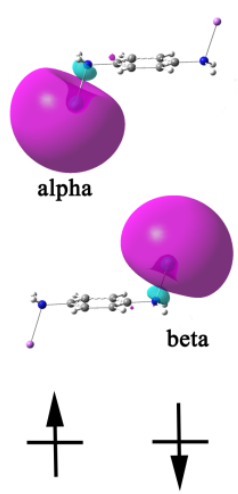

Singlet Diradical

Organic Electride

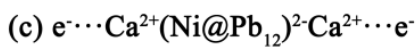
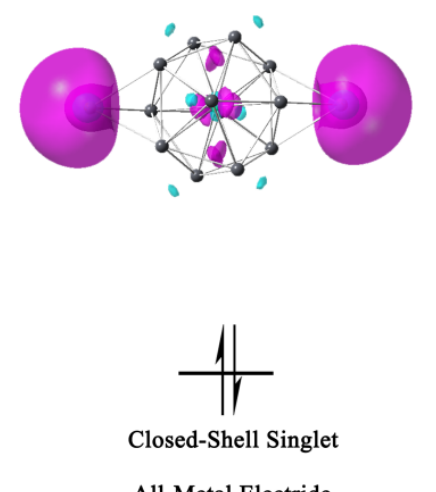
Figure 3 The excess electron orbitals (HOMOs) of (a) $\mathrm{e}^{-\cdots} \mathrm{Ca}^{+} \mathrm{F} \cdots \mathrm{FCa}^{+} \cdots \mathrm{e}^{-}$(b) $\mathrm{e}^{-\cdots} \mathrm{Li}^{+} \mathrm{NH}_{2} \mathrm{PhNH}_{2} \mathrm{Li}^{+} \cdots \mathrm{e}^{-}$and (c) $\mathrm{e}^{-\cdots} \mathrm{Ca}^{2+}\left(\mathrm{Ni} @ \mathrm{~Pb}_{12}\right)^{2-} \mathrm{Ca}^{2+\cdots} \mathrm{e}^{-}$. For the all-metal electride molecule $\mathrm{e}^{-\cdots} \mathrm{Ca}^{2+}\left(\mathrm{Ni} @ \mathrm{~Pb}_{12}\right)^{2-} \mathrm{Ca}^{2+} \cdot \mathrm{e}^{-}$, the middle piece of HOMO from all-metal anion cage connects the two excess electron lobes (see c), which quenches the possibility of singlet diradical character.

$\mathrm{e}^{-} \cdots \mathrm{Ca}^{+} \mathrm{F} \cdots \mathrm{FCa}^{+} \cdots \mathrm{e}^{-}$has a nearly pure singlet diradical characteristic, due to the non-interaction between the two excess electrons localized at long enough distance. Its high diradical character is $y_{0}=0.99$, obtained from natural orbital populations of 1.00024 in HOMO and 0.99976 in LUMO. For the organic electride, the complexant has no contribution to excess electron orbital (HOMO). Thus, the $\mathrm{e}^{-\cdots} \mathrm{Li}^{+} \mathrm{NH}_{2} \mathrm{PhNH}_{2} \mathrm{Li}^{+} \cdots \mathrm{e}^{-}$is also a singlet diradical with $y_{0}=0.99$. However, the all-metal electride molecule $\mathrm{e}^{-\cdots} \mathrm{Ca}^{2+}\left(\mathrm{Ni} @ \mathrm{~Pb}_{12}\right)^{2-} \mathrm{Ca}^{2+} \cdots \mathrm{e}^{-}$with $y_{0}=0$ is in fact a singlet closed shell molecule. The piece of its HOMO from all-metal anion cage $\left(\mathrm{Ni} @ \mathrm{~Pb}_{12}\right)^{2-}$ connects two the excess electron lobes, indicating an interaction between two excess electrons. So the possible singlet diradical character is quenched.

\subsection{The Role of All-Metal Electride Molecules as NLO Switches}

As mentioned before, some organic molecules, ${ }^{60,62}$ organometallic complexes ${ }^{32}$ have non-centrosymmetry and switchable first hyperpolarizability, so they may serve as NLO switch molecules. Recently, we have found that the organic electride molecule $\mathrm{e}^{-} \cdots \mathrm{K}(1)^{+} \cdots$ calix[4]pyrrole $\cdots \mathrm{K}(2)^{+} \cdots \mathrm{e}^{-}$, which has two isolated excess electrons, may also serve as external electric field driven NLO switch molecule. ${ }^{63}$ However, an NLO switch of novel all-metal electrides molecule has not been reported although it be expected. 
The all-metal electride molecules $\mathrm{M}\left(\mathrm{Ni} @ \mathrm{~Pb}_{12}\right) \mathrm{M}(\mathrm{M}=\mathrm{Be}, \mathrm{Mg}$ and $\mathrm{Ca})$ with centrosymmetry have loosely-bound excess electrons, which are easily polarized and cause a strong shift in the electron density. Naturally, a small stimulus of an external electric field may alter the electron density of the molecule, which will bring high

Table 3 Effects of external electric field $F$ on the static electronic first hyperpolarizability $\beta_{0}^{e}(F) / 10^{3}$ and $\beta_{z z Z}^{e}(F) / 10^{3}$, in parentheses, computed at the field-dependent optimized structures.

\begin{tabular}{cccc}
\hline$F / 10^{-4} \mathrm{au}$ & $\mathrm{Be}\left(\mathrm{Ni} @ \mathrm{~Pb}_{12}\right) \mathrm{Be}$ & $\mathrm{Mg}\left(\mathrm{Ni} @ \mathrm{~Pb}_{12}\right) \mathrm{Mg}$ & $\mathrm{Ca}\left(\mathrm{Ni} @ \mathrm{~Pb}_{12}\right) \mathrm{Ca}$ \\
\hline 0 & $0(0)$ & $0(0)$ & $0(0)$ \\
4 & $3(5)$ & $118(195)$ & $1500(2500)$ \\
5 & $4(7)$ & $106(174)$ & $1700(2900)$ \\
8 & $8(12)$ & $70(115)$ & $2200(3620)$ \\
10 & $10(15)$ & $50(81)$ & $2100(3600)$ \\
15 & $14(21)$ & $16(24)$ & $1300(2100)$ \\
20 & $17(26)$ & $2(6)$ & $220(360)$ \\
25 & $19(29)$ & $9(18)$ & $320(560)$ \\
30 & $20(31)$ & $9(20)$ & $420(730)$ \\
35 & $22(33)$ & $7(16)$ & $340(600)$ \\
40 & $24(36)$ & $1(8)$ & $200(380)$ \\
\hline
\end{tabular}

NLO contrast. Consequently, an external electric field driven NLO switch of all-metal electride molecule can be expected.

Table 3 shows the static first hyperpolarizabilities $\left(\beta_{0}^{e}(F)\right)$ of the three all-metal molecular electrides within different external electric field strengths. The $\mathrm{M}\left(\mathrm{Ni} @ \mathrm{~Pb}_{12}\right) \mathrm{M}(\mathrm{M}=\mathrm{Be}, \mathrm{Mg}$ and $\mathrm{Ca})$ molecules have centrosymmetric geometrical and electronic structure $\mathrm{e}^{-}+\left(\mathrm{M}^{2+}\right)\left(\mathrm{Ni} @ \mathrm{~Pb}_{12}\right)^{2-}\left(\mathrm{M}^{2+}\right)+\mathrm{e}^{-}$, so, without the interference from external electric field, their $\beta_{0}^{e}(0)$ values are zero. As a result, the all-metal electride molecule $\mathrm{M}\left(\mathrm{Ni} @ \mathrm{~Pb}_{12}\right) \mathrm{M}$ with $\beta_{0}^{e}(F)=0$ is the off form in NLO contrast. When external electric field is applied, the partial excess electrons gradually transfer from one side $\mathrm{M} 1$ through the middle $\left(\mathrm{Ni} @ \mathrm{~Pb}_{12}\right)^{2-}$ to the other side $\mathrm{M} 2$. In 17 / 38 
consequence, its centrosymmetric electronic structure will be broken, and then a high $\beta_{0}^{e}(F)$ contrast may occur.

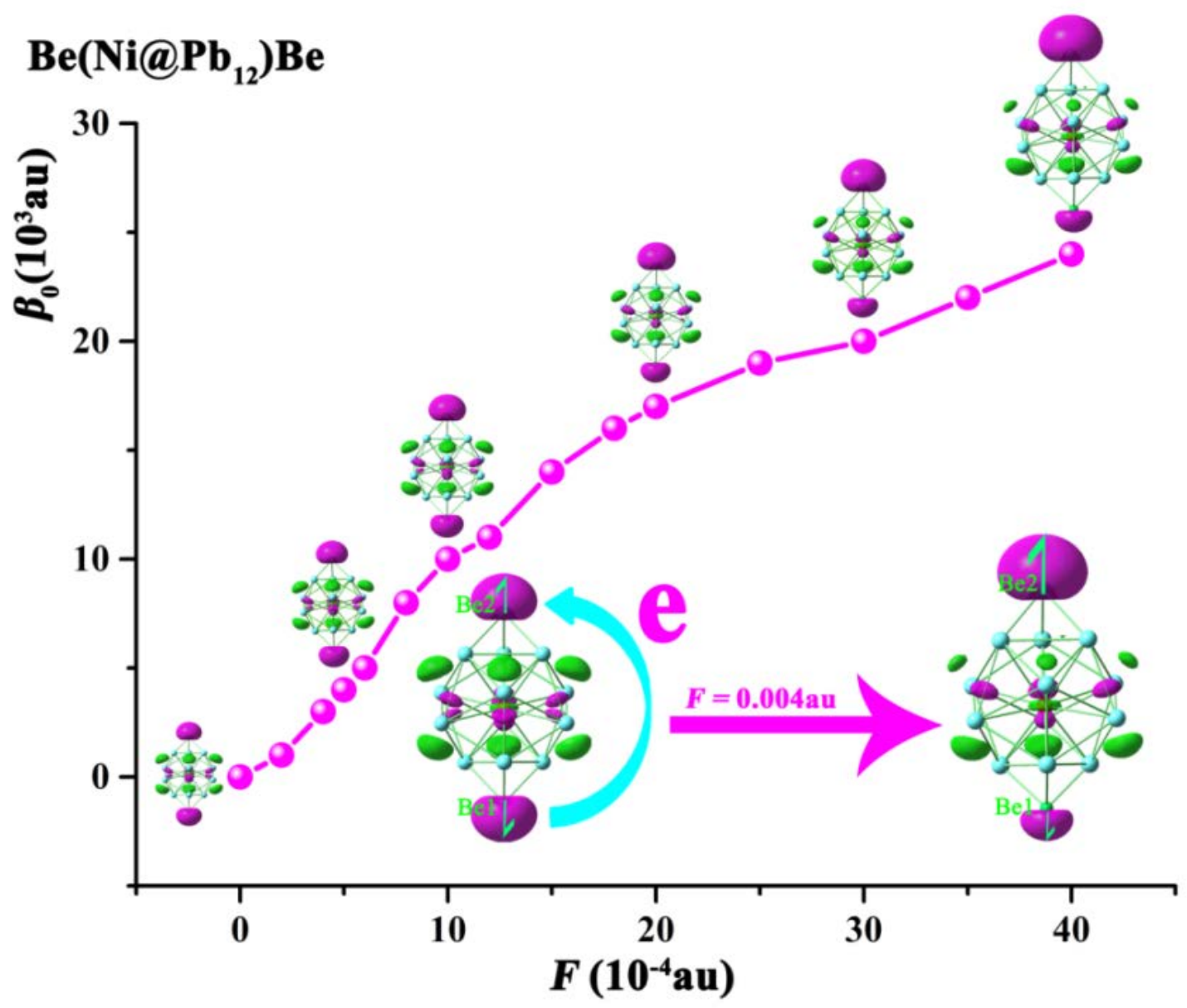

Figure 4 Evolutions of $\beta_{0}^{e}(F)$ and excess electron orbital (HOMO) of Be(Ni@Pb $\left.{ }_{12}\right)$ Be with increasing electric field strength (See Table S4).

For $\mathrm{Be}\left(\mathrm{Ni} @ \mathrm{~Pb}_{12}\right) \mathrm{Be}$, for all the range of studied electric field strengths, its electronic $\beta_{0}^{e}(F)$ value increases when electric field increases. Hence, the function $\beta_{0}^{e}(F)$ could be approximated to a monotonically increasing curve as it is shown in Figure 4. Then, the maximum $\beta_{0}^{e}(F)$ value of $2.4 \times 10^{4}$ au corresponds to the maximum studied electric field strength $F=40 \times 10^{-4}$ au, which is thus selected as the working electric field $\left(F_{w}\right)$. The $\beta_{0}^{e}(F)$ value increases from 0 (off form, $F=0$ ) to the largest $\beta_{0}^{e}\left(F_{w}\right)$ value of $2.4 \times 10^{4}$ au (on form, $F_{w}=40 \times 10^{-4}$ au), so the on/off 18 / 38 
manipulation of NLO switch Be(Ni@Pb $\left.{ }_{12}\right)$ Be can be performed using $F=40 \times 10^{-4}$ au and $F=0$, respectively. In Figure 4 it is also exhibited the field-dependent evolution of excess electron HOMO (in shape and lobe size) of $\mathrm{Be}\left(\mathrm{Ni} @ \mathrm{~Pb}_{12}\right) \mathrm{Be}$ which shows a clear correlation between with the $\beta_{0}^{e}(F)$ value. When the external electric field increases, as commented above the two-lobe HOMO gradually evolves toward decreasing the lower lobe and increasing the upper lobe, and the $\beta_{0}^{e}(F)$ value gradually increases. Within the working electric field $F_{w}=40 \times 10^{-4}$ au, HOMO with the smallest lower lobe and the largest upper lobe corresponds to the largest $\beta_{0}^{e}(F)$.

For $\mathrm{Mg}\left(\mathrm{Ni} @ \mathrm{~Pb}_{12}\right) \mathrm{Mg}$, as it is shown in Figure 5, the function $\beta_{0}^{e}(F)$ corresponds to a monopeak curve. The maximum value of $\beta_{0}^{e}(F)$ of $1.18 \times 10^{5}$ au corresponds to the electric field $F=4 \times 10^{-4}$ au (see table 3). So $F=4 \times 10^{-4}$ au can act as the working electric field $F_{w}$ of $\mathrm{Mg}\left(\mathrm{Ni} @ \mathrm{~Pb}_{12}\right) \mathrm{Mg}$. This very small working external electric field transfers part of the excess electron from one end Mg1 atom through the middle $\left(\mathrm{Ni} @ \mathrm{~Pb}_{12}\right)^{2-}$ to the other end $\mathrm{Mg} 2$ atom, which leads to high $\beta_{0}^{e}(F)$ contrast from 0 (off form , $F=0$ ) to the largest $\beta_{0}^{e}(F)$ value of $1.18 \times 10^{5}$ au (on form, $F_{w}=4 \times 10^{-4}$ au). So the on/off manipulation of NLO switch $\mathrm{Mg}\left(\mathrm{Ni} @ \mathrm{~Pb}_{12}\right) \mathrm{Mg}$ can be performed by using small $F=4 \times 10^{-4}$ au and 0 , respectively. From Figure 5, we can also see that the HOMO with double lobes is gradually changed toward decreasing the lower lobe and increasing the upper lobe. Under $F_{w}=$ $4 \times 10^{-4} \mathrm{au}$, the HOMO present small lower lobe and large upper lobe. For external electric fields larger than the working electric field $F_{w}$, an $s$-type excess electron lone 
pair is formed in $\mathrm{HOMO}$, and the electronic structure of $\mathrm{Mg}\left(\mathrm{Ni} @ \mathrm{~Pb}_{12}\right) \mathrm{Mg}$ becomes $\left(\mathrm{Mg}^{2+}\right)\left(\mathrm{Ni} @ \mathrm{~Pb}_{12}\right)^{2-}\left(\mathrm{Mg}^{2+}\right)+2 \mathrm{e}^{-}$.

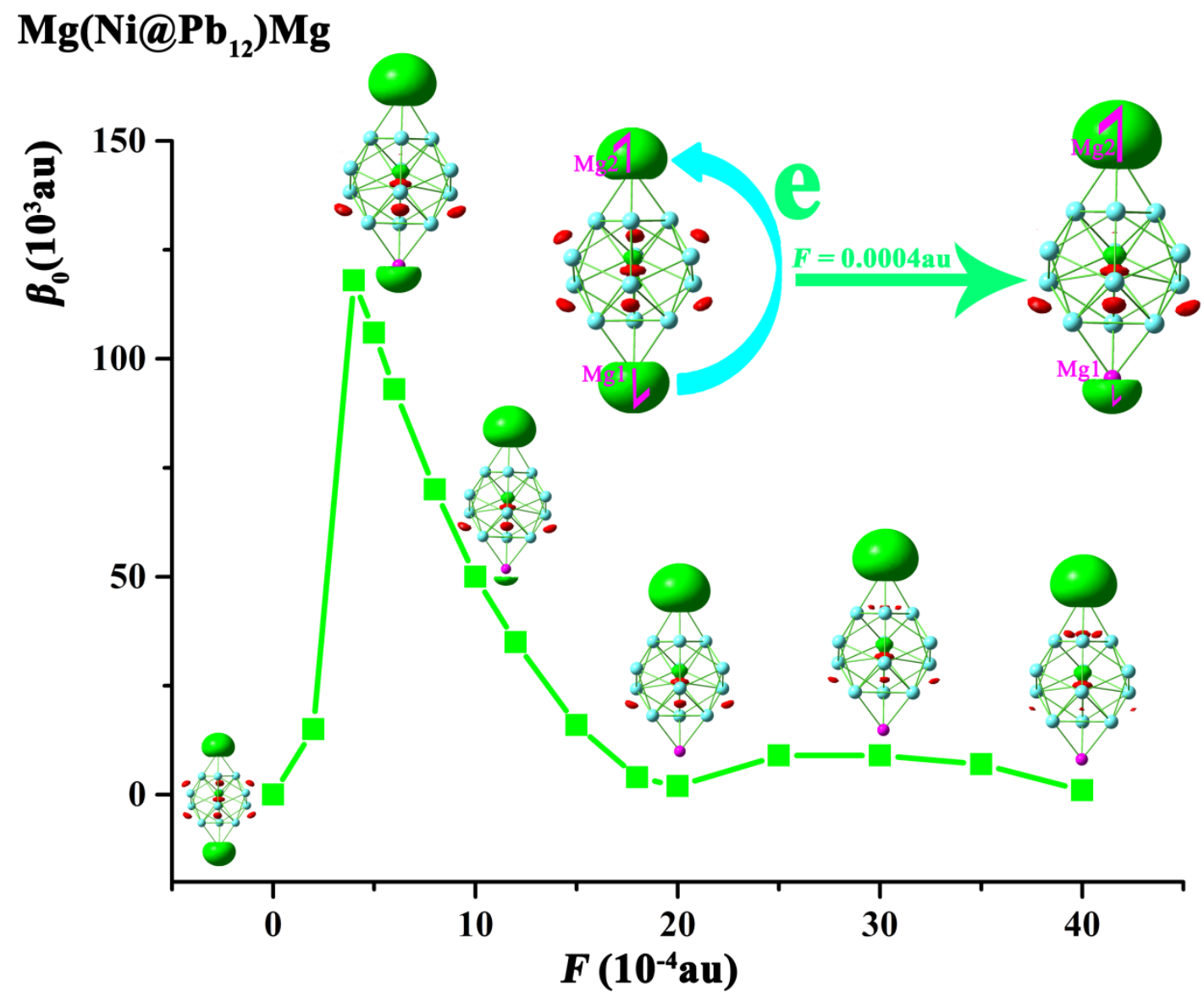

Figure 5 Evolutions of $\beta_{0}^{e}(F)$ and excess electron orbital (HOMO) of $\mathrm{Mg}\left(\mathrm{Ni} @ \mathrm{~Pb}_{12}\right) \mathrm{Mg}$ with increasing electric field strength (See Table S4).

The dependence of $\mathrm{Ca}\left(\mathrm{Ni} @ \mathrm{~Pb}_{12}\right) \mathrm{Ca} \beta_{0}^{e}(F)\left(10^{3} \mathrm{au}\right)$ respect to external electric field strength $F\left(10^{-4} \mathrm{au}\right)$ can also be presented by a monopeak curve, as shown in Figure 6 and table 3. We can see from field-dependent HOMO evolutions that the small nonzero external electric field $F=8 \times 10^{-4}$ au already induces a complete excess electron transfer from one end $\mathrm{Ca} 1$ atom through the middle $\left(\mathrm{Ni} @ \mathrm{~Pb}_{12}\right)^{2-}$ to the other end $\mathrm{Ca} 2$ atom. Then, for $F=8 \times 10^{-4}$ au, an s-type excess electron lone pair is formed and the corresponding electronic structure of the electride molecule becomes $20 / 38$ 
$\left(\mathrm{Ca}^{2+}\right)\left(\mathrm{Ni} @ \mathrm{~Pb}_{12}\right)^{2-}\left(\mathrm{Ca}^{2+}\right)+2 \mathrm{e}^{-}$. As a result, a very high $\beta_{0}^{e}(F)$ contrast occurs. The $\beta_{0}^{e}(F)$ value increases sharply from 0 (off form, $F=0$ ) to the largest $\beta_{0}^{e}(F)$ value of

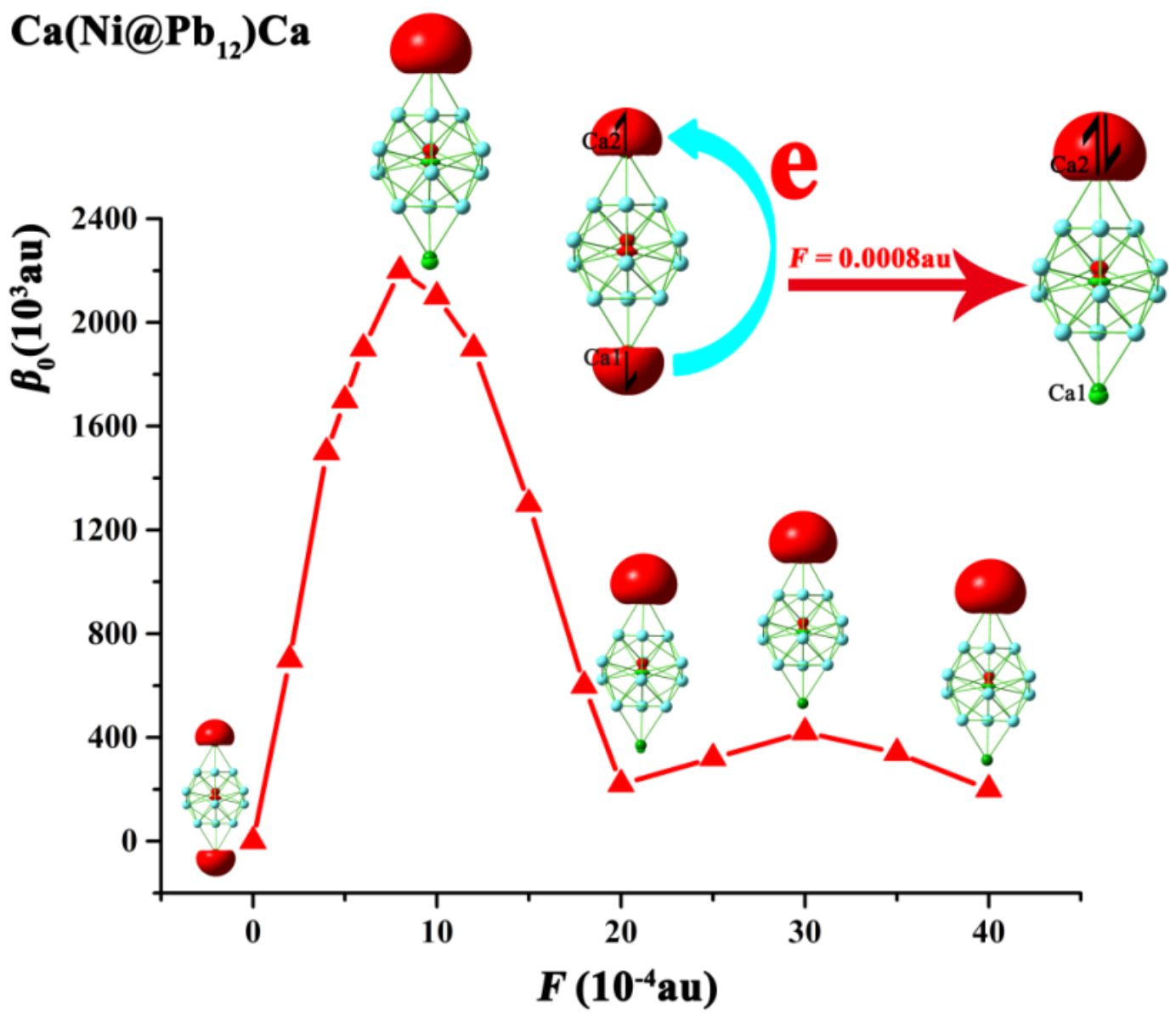

Figure 6 Evolutions of $\beta_{0}^{e}(F)$ and excess electron orbital (HOMO) of $\mathrm{Ca}\left(\mathrm{Ni} @ \mathrm{~Pb}_{12}\right) \mathrm{Ca}$ with increasing electric field strength (See Table S4).

$2.2 \times 10^{6}$ au (on form, $F_{w}=8 \times 10^{-4} \mathrm{au}$ ). So the all metal electride molecule $\mathrm{Ca}\left(\mathrm{Ni} @ \mathrm{~Pb}_{12}\right) \mathrm{Ca}$ displays the optimal NLO switching behavior when are used as off/on forms zero and small $8 \times 10^{-4}$ au fields, respectively.

Above all, our all-metal electrides switch is based on an electronic structure isomerization due to only an excess electron transfer process. Therefore, these new type of switches are associated with a novel nonbonding electronic mechanism, 
instead of a chemical bonding mechanism to alter the molecular geometrical structure. Then the valence and chemical bond nature of the electrides are unchanged in the switching process. This is different from reported cases (forming new valence/bond in altered molecular structure) of chemical change in redox reaction NLO switches and light irradiation NLO switches and so on. Considering the special mechanism of merely altering electronic structure, this switch may be named as electronic structure isomerization switch, while the others are chemical change switches. So such switching should be more sensitive, faster and reversible due to the implementation of a distinctive nonbonding evolution in the electride molecules.

In this work, the field-induced NLO response for an all-metal molecule cannot be explained with the aid of simple two-level model ${ }^{98,99}$ involving electron transitionproperties (see Tables S1, S2 and S3 in the Supporting Information). Nevertheless, some correlations between the maximum $\beta_{0}{ }^{e}\left(F_{w}\right)$ and corresponding transition energy $(\Delta E)$ and the oscillator strength $f_{0}$ are exhibited for these all-metal electride molecules. In Table 4 it is shown that the increasing maximum $\beta_{0}{ }^{e}\left(F_{w}\right)$ order is consistent with the decreasing order of $\Delta E$ and increasing order of $f_{0}$.

Table 4 Working electric field strength $\left(F_{w} / 10^{-4} \mathrm{au}\right)$, the field-dependent electronic contribution to the average static first hyperpolarizability $\left(\beta_{0}{ }^{e}\left(F_{w}\right) / 10^{3} \mathrm{au}\right)$, and the corresponding transition energy $(\Delta E)$, oscillator strength $\left(f_{0}\right)$, and electronic $\left(\beta_{z z z}^{e}\left(F_{w}\right) / 10^{3}\right)$ and vibrational $\left(\beta_{z z z}^{n r}\left(F_{w}\right) / 10^{3}\right)$ contributions to the $\mathrm{z}$ diagonal $\beta$ component (the $\mathrm{z}$ axis is defined as the axis that connects the two alkali metals). $\eta_{\mathrm{nr} / \mathrm{e}}$ is the ratio between $\beta_{z Z Z}^{n r}\left(F_{w}\right)$ and $\beta_{z Z Z}^{e}\left(F_{w}\right)$. 


\begin{tabular}{lcccccccc}
\hline & $\Delta E(\mathrm{eV})$ & $f_{0}$ & transition $^{a}$ & $F_{w}$ & $\beta_{0}^{e}\left(F_{w}\right)$ & $\beta_{z z z}^{e}\left(F_{w}\right)$ & $\beta_{z z z}^{n r}\left(F_{w}\right)$ & $\eta_{\mathrm{nr} / \mathrm{e}}$ \\
\hline $\mathrm{Be}\left(\mathrm{Ni} @ \mathrm{~Pb}_{12}\right) \mathrm{Be}$ & 2.8105 & 0.3651 & $\mathrm{H}-\mathrm{L}+9$ & 40 & 24 & 36 & 170 & 4.7 \\
$\mathrm{Mg}\left(\mathrm{Ni} @ \mathrm{~Pb} \mathrm{P}_{12}\right) \mathrm{Mg}$ & 1.2614 & 0.4190 & $\mathrm{H}-\mathrm{L}$ & 4 & 118 & 195 & 3070 & 15.7 \\
$\mathrm{Ca}\left(\mathrm{Ni} @ \mathrm{~Pb}_{12}\right) \mathrm{Ca}$ & 1.1592 & 1.7350 & $\mathrm{H}-\mathrm{L}$ & 8 & 2200 & 3620 & 9080 & 2.5 \\
\hline
\end{tabular}

${ }^{a} \mathrm{H}=\mathrm{HOMO}, \mathrm{L}=\mathrm{LUMO}$. In the two-state approximation, we selected excited states with maximum $f_{0}$, and the transition with the largest proportion.

The comparison of the HOMO shapes corresponding to the maximum $\beta_{0}{ }^{e}\left(F_{w}\right)$ for the three different all-metal electride is quite interesting. The HOMO present small lower lobe and large upper lobe for Be(Ni@Pb 12$) B e$, almost single lobe (very small lower lobe and very large upper lobe) for $\mathrm{Mg}\left(\mathrm{Ni} @ \mathrm{~Pb}_{12}\right) \mathrm{Mg}$, and a single lobe for $\mathrm{Ca}\left(\mathrm{Ni} @ \mathrm{~Pb}_{12}\right) \mathrm{Ca}$. However, as it can be seen in Figure 4, for $\mathrm{Be}\left(\mathrm{Ni} @ \mathrm{~Pb}_{12}\right) \mathrm{Be}$ the maximum values of $\beta_{0}{ }^{e}\left(F_{w}\right)$ is out of the range of the studied electric field strength. Based on the results obtained for the other two all-metal electride one can assume that also for $\mathrm{Be}\left(\mathrm{Ni} @ \mathrm{~Pb}_{12}\right) \mathrm{Be}$ there will be a correspondence between the maximum value of $\beta_{0}{ }^{e}\left(F_{w}\right)$ and a single lobe or quasi-single lobe shape of the HOMO.

Luis and coworkers have determined and analyzed the vibrational, as compared to the electronic, NLO properties for a representative set of electrides. ${ }^{82}$ The effect of vibrations on the hyperpolarizability can be quite important and may even be much larger than the electronic counterpart. ${ }^{100}$ In Table 4 we present the comparison between the electronic and nuclear relaxation contributions to $\beta_{z z z}^{e}\left(F_{w}\right)$ for the three all-metal electrides. The ratio between the nuclear relaxation and electronic contribution goes from about 2.5 for $\mathrm{Ca}\left(\mathrm{Ni} @ \mathrm{~Pb}_{12}\right) \mathrm{Ca}$ to 16 for $\mathrm{Mg}\left(\mathrm{Ni} @ \mathrm{~Pb}_{12}\right) \mathrm{Mg}$. Then, for the three electrides, $\beta_{z z z}^{n r}(F)$ is far larger than $\beta_{z z z}^{e}(F)$, showing the key 
role of the vibrational contributions in the determination of the nonlinear optical properties of the electrides.

For the NLO molecules, the transparent region of electronic absorption spectrum is selected as its working waveband. The region of the working waveband has great importance in the design of NLO devices. Figure 7 show that the three all-metal electride molecules have infrared (IR) transparent region from 1.5 to $10 \mu \mathrm{m}$ (their infrared region to vibrational excitations is $>25 \mu m$ ). Thus, these three all-metal electride molecules could be used as new IR NLO materials.

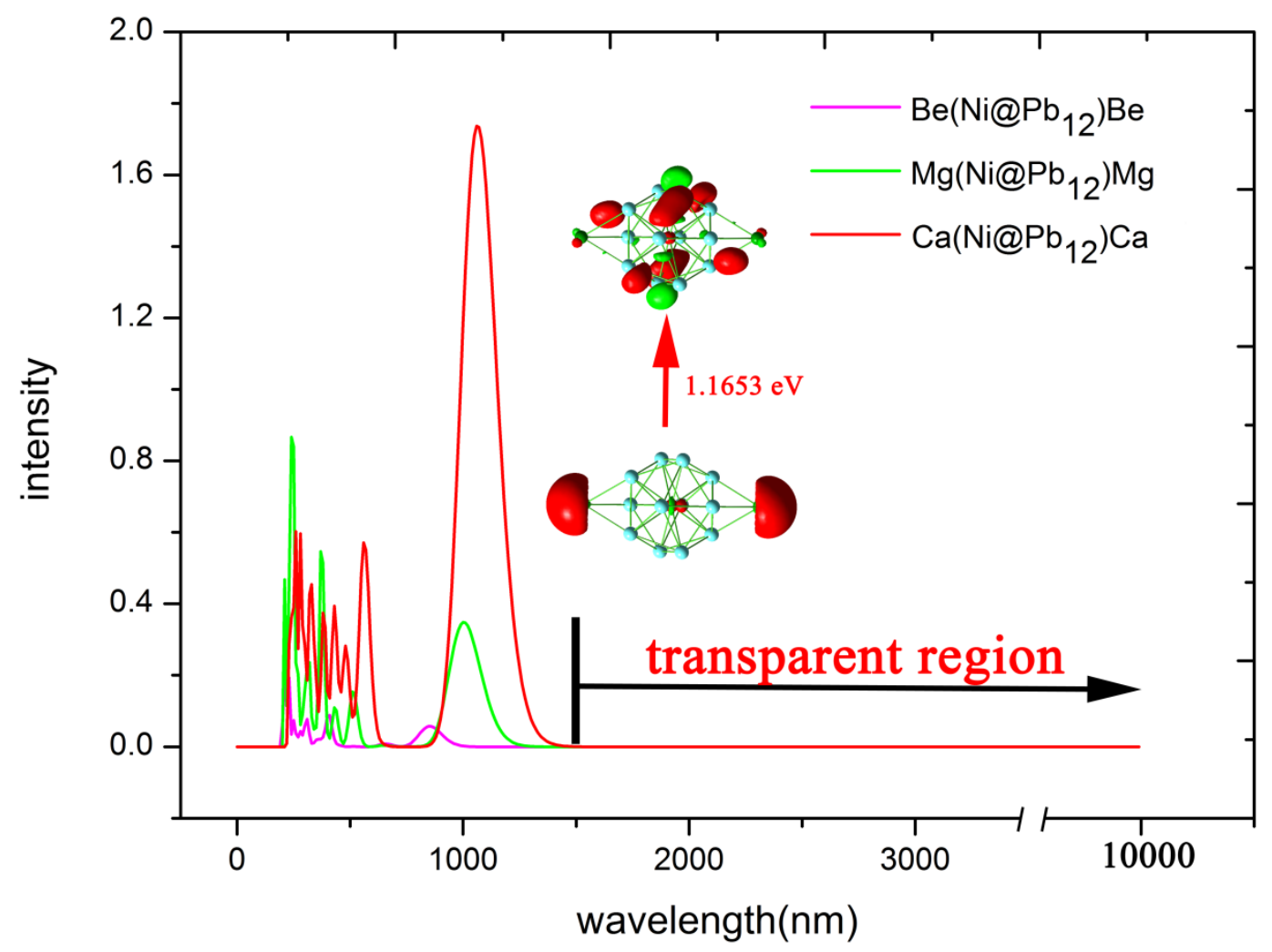

Figure 7 The electronic absorption spectra of the three all-metal electride molecules.

\section{CONCLUSIONS}


In this paper we have shown how to construct a novel NLO molecular switch with IR transparency and centrosymmetry, which is triggered by an external electric field. This could open a key breakthrough in the challenging field of the research of new NLO switches. We have focused on the new concept of all-metal electride. In particular, we have studied the centrosymmetric all-metal electrides $\mathrm{M}\left(\mathrm{Ni} @ \mathrm{~Pb}_{12}\right) \mathrm{M}$ ( $\mathrm{M}=\mathrm{Be}, \mathrm{Mg}$ and $\mathrm{Ca}$ ), which contain loosely-bound anionic excess electrons. These molecular nonlinear optical (NLO) switches, which have been theoretically designed, can be turn on and turn off by an external electric field.

The loosely-bound excess electrons can be very easily polarized. Therefore, the all-metal electride excess electrons can be gradually driven by an external electric field from one lobe to opposite lobe of HOMO orbital. This electron transition causes a high $\beta_{0}$ contrast due to the breaking of the centrosymmetry of the excess electron HOMO orbital. In this new type of electron transfer switch, the valence and chemical bond nature of the electrides are not altered. Then, on the contrary to the usual NLO switches mechanism which implies a molecular structure variation, the all-metal electride switches present a nonbonding distinct switching mechanism that could be named electronic structure isomerization. Certainly, such new type of NLO switches should be high sensitive, fast and reversible. Besides, these all-metal electride molecules have a working waveband in the infrared range $(1.5-10 \mu m)$, and hence are commendable IR NLO switch molecules. This work opens a new research field of an electric field manipulated IR NLO switches of all-metal electride molecules.

\section{ASSOCIATED CONTENT}


Supporting Information. Detailed information for Table S1, S2, S3 and S4 are included. This material is available free of charge via the Internet at http://pubs.acs.org.

\section{AUTHOR INFORMATION}

\section{Corresponding Authors}

*E-mail: wud@jlu.edu.cn (D.Wu)

*E-mail: josepm.luis@udg.edu (Josep M. Luis)

*E-mail: gu@scnu.edu.cn (F-L. Gu)

*E-mail: lzr@jlu.edu.cn (Z.-R. Li)

\section{Notes}

The authors declare no competing financial interest.

\section{ACKNOWLEDGMENT}

This study was supported by the National Natural Science Foundation of China (Grant Nos. 21573089, 21303066, 21173095, 21403083, 21603082, 21403075, 21673085), the State Key Development Program for Basic Research of China (Grant No. 2013CB834801), the Graduate Innovation Fund of Jilin University (Grant No. 2016158), the Spanish Ministerio de Economia y competividad (MINECO, CTQ2014-52525-P) and the Generalitat de Catalunya (project number 2014SGR931).

\section{REFERENCES}

(1) Dye, J. L. Electrides: Early Examples of Quantum Confinement. Accounts chem. Res. 2009, 42, 1564-1572. 
(2) Dye, J. L. Electrides: Ionic Salts with Electrons as the Anions. Science 1990, 247, 663-668.

(3) Dye, J. L. Anionic Electron in Electrides. Nature 1993, 365, 10-11.

(4) Dye, J. L. Electrides: From 1D Heisenberg Chains to 2d Pseudo-Metals. Inorg. Chem. 1997, 36, 3816-3826.

(5) Dye, J. L. Electrons as Anions. Science 2003, 301, 607-608.

(6) Dye, J. L.; Wagner, M. J.; Overney, G.; Huang, R. H.; Nagy, T. F.; Tomanek, D. Cavities and Channels in Electrides. J. Am. Chem. Soc. 1996, 118, 7329-7336.

(7) Ichimura, A. S.; Dye, J. L.; Camblor, M. A.; Villaescusa, L. A. Toward Inorganic Electrides. J. Am. Chem. Soc. 2002, 124, 1170-1171.

(8) Matsuishi, S.; Toda, Y.; Miyakawa, M.; Hayashi, K.; Kamiya, T.; Hirano, M.; Tanaka, I.; Hosono, H. High-Density Electron Anions in a Nanoporous Single Crystal:[Ca $\left.\mathrm{Ca}_{24} \mathrm{Al}_{28} \mathrm{O}_{64}\right]^{4+}(4 \mathrm{e}-)$. Science 2003, 301, 626-629.

(9) Hosono, H. Two Classes of Superconductors Discovered in Our Material Research: Iron-Based High Temperature Superconductor and Electride Superconductor. Physica C 2009, 469, 314-325.

(10)Li, Y.; Li, Z. R.; Wu, D.; Li, R. Y.; Hao, X. Y.; Sun, C. C. An Ab Initio Prediction of the Extraordinary Static First Hyperpolarizability for the Electron-Solvated Cluster (FH) $)_{2}\{\mathrm{e}\}(\mathrm{HF})$. J. Phys. Chem. B 2004, 108, 3145-3148.

(11)Chen, W.; Li, Z. R.; Wu, D.; Gu, F. L.; Hao, X. Y.; Wang, B. Q.; Li, R. J.; Sun, C. C. The Static Polarizability and First Hyperpolarizability of the Water Trimer Anion: Ab Initio Study. J. Chem. Phys. 2004, 121, 10489-10494.

(12)Zhong, R.-L.; Xu, H.-L.; Li, Z.-R.; Su, Z.-M. Role of Excess Electrons in Nonlinear Optical Response. J. Phys. Chem. Lett. 2015, 6, 612-619.

(13)Dye, J. L. Anionic Electrons in Electrides. Nature 1993, 365, 10-11.

(14)Dye, J. L. Chemistry. Electrons as Anions. Science 2003, 301, 607-608.

(15)Lee, K.; Kim, S. W.; Toda, Y.; Matsuishi, S.; Hosono, H. Dicalcium Nitride as a Two-Dimensional Electride with an Anionic Electron Layer. Nature 2013, 494, 336-340. 
(16)Chen, W.; Li, Z. R.; Wu, D.; Li, Y.; Sun, C. C.; Gu, F. L. The Structure and the Large Nonlinear Optical Properties of Li@Calix[4]Pyrrole. J. Am. Chem. Soc. 2005, 127, 10977-10981.

(17)Wang, J.-J.; Zhou, Z.-J.; Bai, Y.; Liu, Z.-B.; Li, Y.; Wu, D.; Chen, W.; Li, Z.-R.; Sun, C.-C. The Interaction between Superalkalis $\left(\mathrm{M}_{3} \mathrm{O}, \mathrm{M}=\mathrm{Na}, \mathrm{K}\right)$ and a $\mathrm{C}_{20} \mathrm{~F}_{20}$ Cage Forming Superalkali Electride Salt Molecules with Excess Electrons inside the $\mathrm{C}_{20} \mathrm{~F}_{20}$ Cage: Dramatic Superalkali Effect on the Nonlinear Optical Property. J.Mater.Chem. 2012, 22, 9652-9657.

(18)Bai, Y.; Zhou, Z.-J.; Wang, J.-J.; Li, Y.; Wu, D.; Chen, W.; Li, Z.-R.; Sun, C.-C. New Acceptor-Bridge-Donor Strategy for Enhancing NLO Response with Long-Range Excess Electron Transfer from the $\mathrm{NH}_{2} \cdots \mathrm{M} / \mathrm{M}_{3} \mathrm{O}$ Donor $(\mathrm{M}=\mathrm{Li}, \mathrm{Na}, \mathrm{K})$ to inside the Electron Hole Cage $\mathrm{C}_{20} \mathrm{~F}_{19}$ Acceptor through the Unusual Sigma Chain Bridge $\left(\mathrm{CH}_{2}\right)_{4}$. J. Phys. Chem. A 2013, 117, 2835-2843.

(19)Xu, H. L.; Li, Z. R.; Wu, D.; Wang, B. Q.; Li, Y.; Gu, F. L.; Aoki, Y. Structures and Large NLO Responses of New Electrides: Li-Doped Fluorocarbon Chain. J. Am. Chem. Soc. 2007, 129, 2967-2970.

(20)He, H.-M.; Li, Z.-R.; Li, Y.; Sun, W.-M.; Wang, J.-J.; Liu, J.-y.; Wu, D. Unusual Manipulative Effects of Spin Multiplicity and Excess Electron Number on the Structure and Nonlinear Optical Response in New Linear and Cyclic Electride Molecules with Multiexcess Electrons. J. Phys. Chem. C 2014, 118, 23937-23945.

(21)Postils, V.; Garcia-Borras, M.; Sola, M.; Luis, J. M.; Matito, E. On the Existence and Characterization of Molecular Electrides. Chem. Commun. 2015, 51, 4865-4868.

(22)Lee, C.; Whangbo, M. H.; Köhler, J. Analysis of Electronic Structures and Chemical Bonding of Metal - Rich Compounds. 2. Presence of Dimer $(\mathrm{T}-\mathrm{T})^{4-}$ and Isolated $\mathrm{T}^{2-}$ Anions in the Polar Intermetallic $\mathrm{Cr}_{5} \mathrm{~B}_{3}{ }^{-}$Type Compounds $\mathrm{AE}_{5} \mathrm{~T}_{3}(\mathrm{AE}=$ Ca, Sr; T = Au, Ag, Hg, Cd, Zn). Anorg. Allg. Chem. 2010, 636, 36-40.

(23)Kazem, N.; Xie, W.; Ohno, S.; Zevalkink, A.; Miller, G. J.; Snyder, G. J.; Kauzlarich, S. M. High-Temperature Thermoelectric Properties of the Solid-Solution Zintl Phase $\mathrm{Eu}_{11} \mathrm{Cd}_{6} \mathrm{Sb}_{12-\mathrm{x}} \mathrm{As}_{\mathrm{x}}(\mathrm{x}<3)$. Chem. Mater. 2014, 26, 1393-1403. 
(24)Benda, C. B.; Waibel, M.; Fässler, T. F. Cover Picture: On the Formation of Intermetalloid Clusters: Titanocene (III) Diammin as a Versatile Reactant toward Nonastannide Zintl Clusters. Angew. Chem. Int. Edit. 2015, 54, 365-365.

(25)Bentlohner, M. M.; Klein, W.; Fard, Z. H.; Jantke, L. A.; Fässler, T. F. Linking Deltahedral Zintl Clusters with Conjugated Organic Building Blocks: Synthesis and Characterization of the Zintl Triad [R-Geg- $\left.\mathrm{CH} \equiv \mathrm{CH} \equiv \mathrm{CH} \equiv \mathrm{CH}-\mathrm{Ge}_{9}-\mathrm{R}\right]^{4-}$. Angew. Chem. 2015, 127, 3819-3824.

(26)Benda, C. B.; Waibel, M.; Fässler, T. F. On the Formation of Intermetalloid Clusters: Titanocene (III) Diammin as a Versatile Reactant toward Nonastannide Zintl Clusters. Angew. Chem. Int. Edit. 2015, 54, 522-526.

(27) Reveles, J. U.; Clayborne, P. A.; Reber, A. C.; Khanna, S. N.; Pradhan, K.; Sen, P.; Pederson, M. R. Designer Magnetic Superatoms. Nat. Chem. 2009, 1, 310-315.

(28)He, H.-M.; Li, Y.; Sun, W.-M.; Wang, J.-J.; Wu, D.; Zhong, R.-L.; Zhou, Z.-J.; Li, Z.-R. All-Metal Electride Molecules CuAg@Ca7M (M= Be, Mg, and Ca) with Multi-Excess Electrons and All-Metal Polyanions: Molecular Structures and Bonding Modes as Well as Large Infrared Nonlinear Optical Responses. Dalton Trans. 2016.

(29)Daub, J.; Salbeck, J.; Knöchel, T.; Fischer, C.; Kunkely, H.; Rapp, K. M. Ligh-Sensitive Molecular Building Blocks with Electron Transfer Activity: Synthesis and Properties of a Photochemically Switchable, Dicyanovinyl-Substituted Furan. Angew. Chem. Int. Edit. 1989, 28, 1494-1496.

(30)Feringa, B. L.; Jager, W. F.; de Lange, B. Organic Materials for Reversible Optical Data Storage. Tetrahedron 1993, 49, 8267-8310.

(31)Kurumida, J.; Yoo, S. B. Nonlinear Optical Signal Processing in Optical Packet Switching Systems. IEEE J. Sel. Top. Quant 2012, 18, 978-987.

(32)Champagne, B.; Plaquet, A. l.; Pozzo, J.-L.; Rodriguez, V.; Castet, F. d. r. Nonlinear Optical Molecular Switches as Selective Cation Sensors. J. Am.Chem. Soc. 2012, 134, 8101-8103. 
(33)Loucif-Saibi, R.; Nakatani, K.; Delaire, J.; Dumont, M.; Sekkat, Z. Photoisomerization and Second Harmonic Generation in Disperse Red One-Doped and-Functionalized Poly (Methyl Methacrylate) Films. Chem. Mater. 1993, 5, 229-236.

(34)Gilat, S. L.; Kawai, S. H.; Lehn, J. M. Light-Triggered Molecular Devices: Photochemical Switching of Optical and Electrochemical Properties in Molecular Wire Type Diarylethene Species. Chem.- Eur. J. 1995, 1, 275-284.

(35)Kawata, S.; Kawata, Y. Three-Dimensional Optical Data Storage Using Photochromic Materials. Chem. Rev. 2000, 100, 1777-1788.

(36) Sliwa, M.; Létard, S.; Malfant, I.; Nierlich, M.; Lacroix, P. G.; Asahi, T.; Masuhara, H.; Yu, P.; Nakatani, K. Design, Synthesis, Structural and Nonlinear Optical Properties of Photochromic Crystals: Toward Reversible Molecular Switches. Chem. Mater. 2005, 17, 4727-4735.

(37) Aubert, V.; Guerchais, V.; Ishow, E.; Hoang-Thi, K.; Ledoux, I.; Nakatani, K.; Le Bozec, H. Efficient Photoswitching of the Nonlinear Optical Properties of Dipolar Photochromic Zinc (II) Complexes. Angew. Chem. 2008, 120, 587-590.

(38)Song, P.; Gao, A.-H.; Zhou, P.-W.; Chu, T.-S. Theoretical Study on Photoisomerization Effect with a Reversible Nonlinear Optical Switch for Dithiazolylarylene. J. Phys. Chem. A 2012, 116, 5392-5397.

(39) Boixel, J.; Guerchais, V. r.; Le Bozec, H.; Jacquemin, D.; Amar, A.; Boucekkine, A.; Colombo, A.; Dragonetti, C.; Marinotto, D.; Roberto, D. Second-Order Nlo Switches from Molecules to Polymer Films Based on Photochromic Cyclometalated Platinum (II) Complexes. J. Am. Chem. Soc. 2014, 136, 5367-5375.

(40) Sanguinet, L.; Pozzo, J.-L.; Rodriguez, V.; Adamietz, F.; Castet, F.; Ducasse, L.; Champagne, B. Acido-and Phototriggered NLO Properties Enhancement. J. Phys. Chem. B 2005, 109, 11139-11150.

(41) Sanguinet, L.; Pozzo, J.-L.; Guillaume, M.; Champagne, B.; Castet, F.; Ducasse, L.; Maury, E.; Soulié, J.; Mançois, F.; Adamietz, F. Acidoswitchable 
Nlo-Phores: Benzimidazolo [2,3-B] Oxazolidines. J. Phys. Chem. B 2006, 110, 10672-10682.

(42)Mançois, F.; Sanguinet, L.; Pozzo, J.-L.; Guillaume, M.; Champagne, B.; Rodriguez, V.; Adamietz, F.; Ducasse, L.; Castet, F. Acido-Triggered Nonlinear Optical Switches: Benzazolo-Oxazolidines. J. Phys. Chem. B 2007, 111, 9795-9802.

(43)Coe, B. J. Molecular Materials Possessing Switchable Quadratic Nonlinear Optical Properties. Chem.- Eur. J. 1999, 5, 2464-2471.

(44)Coe, B. J.; Houbrechts, S.; Asselberghs, I.; Persoons, A. Efficient, Reversible Redox-Switching of Molecular First Hyperpolarizabilities in Ruthenium (II) Complexes Possessing Large Quadratic Optical Nonlinearities. Angew. Chem. Int. Edit. 1999, 38, 366-369.

(45) Malaun, M.; Reeves, Z. R.; Paul, R. L.; Jeffery, J. C.; McCleverty, J. A.; Ward, M. D.; Asselberghs, I.; Clays, K.; Persoons, A. Reversible Switching of the First Hyperpolarisability of an Nlo-Active Donor-Acceptor Molecule Based on Redox Interconversion of the Octamethylferrocene Donor Unit. Chem. Commun. 2001, 49-50.

(46)Boubekeur-Lecaque, L.; Coe, B. J.; Clays, K.; Foerier, S.; Verbiest, T.; Asselberghs, I. Redox-Switching of Nonlinear Optical Behavior in Langmuir-Blodgett Thin Films Containing a Ruthenium (II) Ammine Complex. J. Am. Chem. Soc. 2008, 130, 3286-3287.

(47)Wang, W.-Y.; Ma, N.-N.; Sun, S.-L.; Qiu, Y.-Q. Impact of Redox Stimuli on Ferrocene-Buckybowl Complexes: Switchable Optoelectronic and Nonlinear Optical Properties. Organometallics 2014, 33, 3341-3352.

(48)Castet, F.; Rodriguez, V.; Pozzo, J.-L.; Ducasse, L.; Plaquet, A.; Champagne, B. Design and Characterization of Molecular Nonlinear Optical Switches. Accounts Chem. Res. 2013, 46, 2656-2665.

(49)Samoc, M.; Gauthier, N.; Cifuentes, M. P.; Paul, F.; Lapinte, C.; Humphrey, M. G. Electrochemical Switching of the Cubic Nonlinear Optical Properties of an Aryldiethynyl-Linked Heterobimetallic Complex between Three Distinct States. Angew. Chem. Int. Edit. 2006, 45, 7376-7379. 
(50)Li, P. X.; Wang, M. S.; Zhang, M. J.; Lin, C. S.; Cai, L. Z.; Guo, S. P.; Guo, G. C. Electron-Transfer Photochromism to Switch Bulk Second-Order Nonlinear Optical Properties with High Contrast. Angew. Chem. Int. Edit. 2014, 53, 11529-11531.

(51)Fusil, S.; Garcia, V.; Barthélémy, A.; Bibes, M. Magnetoelectric Devices for Spintronics. Annu. Rev. Mater. Res. 2014, 44, 91-116.

(52) Tsymbal, E. Y. Spintronics: Electric Toggling of Magnets. Nat. Mater. 2012, $11,12-13$

(53)Heron, J.; Bosse, J.; He, Q.; Gao, Y.; Trassin, M.; Ye, L.; Clarkson, J.; Wang, C.; Liu, J.; Salahuddin, S. Deterministic Switching of Ferromagnetism at Room Temperature Using an Electric Field. Nature 2014, 516, 370-373.

(54)Bollinger, A. T.; Dubuis, G.; Yoon, J.; Pavuna, D.; Misewich, J.; Božović, I. Superconductor-Insulator Transition in $\mathrm{La}_{2-\mathrm{x}} \mathrm{Sr}_{\mathrm{x}} \mathrm{CuO}_{4}$ at the Pair Quantum Resistance. Nature 2011, 472, 458-460.

(55)Ueno, K.; Nakamura, S.; Shimotani, H.; Ohtomo, A.; Kimura, N.; Nojima, T.; Aoki, H.; Iwasa, Y.; Kawasaki, M. Electric-Field-Induced Superconductivity in an Insulator. Nat. Mater. 2008, 7, 855-858.

(56)Li, L.; O’Farrell, E.; Loh, K.; Eda, G.; Özyilmaz, B.; Neto, A. C. Controlling Many-Body States by the Electric-Field Effect in a Two-Dimensional Material. Nature 2015.

(57) Novoselov, K. S.; Geim, A. K.; Morozov, S.; Jiang, D.; Zhang, Y.; Dubonos, S. a.; Grigorieva, I.; Firsov, A. Electric Field Effect in Atomically Thin Carbon Films. Science 2004, 306, 666-669.

(58)Kirtman, B.; Champagne, B.; Bishop, D. M. Electric Field Simulation of Substituents in Donor-Acceptor Polyenes: A Comparison with Ab Initio Predictions for Dipole Moments, Polarizabilities, and Hyperpolarizabilities. J. Am. Chem. Soc. 2000, 122, 8007-8012.

(59) Margulis, V. A.; Gaiduk, E.; Zhidkin, E. Electric-Field-Induced Optical Second-Harmonic Generation and Nonlinear Optical Rectification in Semiconducting Carbon Nanotubes. Opt. Commun. 2000, 183, 317-326. 
(60) Nakano, M.; Minami, T.; Yoneda, K.; Muhammad, S.; Kishi, R.; Shigeta, Y.; Kubo, T.; Rougier, L. a.; Champagne, B. t.; Kamada, K.; Ohta, K. Giant Enhancement of the Second Hyperpolarizabilities of Open-Shell Singlet Polyaromatic Diphenalenyl Diradicaloids by an External Electric Field and Donor-Acceptor Substitution. J. Phys. Chem. Lett. 2011, 2, 1094-1098.

(61)Bai, Y.; Zhou, Z.-J.; Wang, J.-J.; Li, Y.; Wu, D.; Chen, W.; Li, Z.-R.; Sun, C.-C. The Effects of External Electric Field: Creating Non-Zero First Hyperpolarizability for Centrosymmetric Benzene and Strongly Enhancing First Hyperpolarizability for Non-Centrosymmetric Edge-Modified Graphene Ribbon $\mathrm{H}_{2} \mathrm{~N}-(3,3) Z G N R-N_{2}$. J. Mol. Model. 2013, 19, 3983-3991.

(62)Lamère, J. F.; Lacroix, P. G.; Farfán, N.; Rivera, J. M.; Santillan, R.; Nakatani, K. Synthesis, Characterization and Nonlinear Optical (Nlo) Properties of a Push-Pull Bisboronate Chromophore with a Potential Electric Field Induced Nlo Switch. J. Mater. Chem. 2006, 16, 2913-2920.

(63)Wang, J.-J.; Zhou, Z.-J.; He, H.-M.; Wu, D.; Li, Y.; Li, Z.-R.; Zhang, H.-X. An External Electric Field Manipulated Second-Order Nonlinear Optical Switch of an Electride Molecule: A Long-Range Electron Transfer Forms a Lone Excess Electron Pair and Quenches Singlet Diradical. J. Phys. Chem. C 2016, 120, 13656-13666.

(64) Petrucci, R. H.; Harwood, W. S.; Herring, F. G. General Chemistry: Principles and Modern Applications; Prentice Hall, 2002.

(65)Housecroft, C.; Sharpe, A.; Prentice Hall, New York, 2005.

(66)Zhao, S.; Li, Z.-H.; Wang, W.-N.; Liu, Z.-P.; Fan, K.-N.; Xie, Y.; Schaefer III, H. F. Is the Uniform Electron Gas Limit Important for Small Ag Clusters? Assessment of Different Density Functionals for $\operatorname{Ag}_{n}$ (n $\left.\leq 4\right)$. J. Chem. Phys. 2006, 124, 184102.

(67)Li, S.; Hennigan, J. M.; Dixon, D. A.; Peterson, K. A. Accurate Thermochemistry for Transition Metal Oxide Clusters. J. Phys. Chem. A 2009, 113, 7861-7877. 
(68)Bühl, M.; Reimann, C.; Pantazis, D. A.; Bredow, T.; Neese, F. Geometries of Third-Row Transition-Metal Complexes from Density-Functional Theory. J. Chem. Theory Comput. 2008, 4, 1449-1459.

(69) Carter, E.; Sharples, K. M.; Platts, J. A.; Murphy, D. M. Structure Determination of Bound Nitrogen-Based Adducts with Copper (II) Acetylacetonato; an Epr, Endor and DFT Study. Phys. Chem. Chem. Phys. 2015, 17, 11445-11454.

(70)Jiménez-Sánchez, A.; Ortiz, B.; Navarrete, V. O.; Flores, J. C.; Farfán, N.; Santillan, R. A Dual-Model Fluorescent $\mathrm{Zn}^{2+} / \mathrm{Cu}^{2+}$ Ions Sensor with in-Situ Detection of $\mathrm{S}^{2-} /\left(\mathrm{PO}_{4}\right)^{-}$and Colorimetric Detection of $\mathrm{Fe}^{2+}$ Ion. Inorg. Chim. Acta 2015, 429, 243-251.

(71)Hay, P. J.; Wadt, W. R. Ab Initio Effective Core Potentials for Molecular Calculations. Potentials for K to Au Including the Outermost Core Orbitals. J. Chem. Phys. 1985, 82, 299-310.

(72)Wadt, W. R.; Hay, P. J. Ab Initio Effective Core Potentials for Molecular Calculations. Potentials for Main Group Elements Na to Bi. J. Chem. Phys. 1985, 82, 284-298.

(73)Hay, P. J.; Wadt, W. R. Ab Initio Effective Core Potentials for Molecular Calculations. Potentials for the Transition Metal Atoms Sc to Hg. J. Chem. Phys. 1985, 82, 270-283.

(74)Bilbrey, J. A.; Kazez, A. H.; Locklin, J.; Allen, W. D. Exact Ligand Cone Angles. J. Comput. Chem. 2013, 34, 1189-1197.

(75) Nakano, M.; Champagne, B.; Botek, E.; Ohta, K.; Kamada, K.; Kubo, T. Giant Electric Field Effect on the Second Hyperpolarizability of Symmetric Singlet Diradical Molecules. J. Chem. Phys. 2010, 133, 154302-154302.

(76) Karamanis, P. The Importance of the DFT Method on the Computation of the Second Hyperpolarizability of Semiconductor Clusters of Increasing Size: A Critical Analysis on Prolate Aluminum Phosphide Clusters. Int. J. Quantum Chem. 2012, 112, 2115-2125.

(77) Maroulis, G. Electric (Hyper) Polarizability Derivatives for the Symmetric Stretching of Carbon Dioxide. Chem. Phys. 2003, 291, 81-95. 
(78)Maroulis, G. Electric Dipole Hyperpolarizability and Quadrupole Polarizability of Methane from Finite-Field Coupled Cluster and Fourth-Order Many-Body Perturbation Theory Calculations. Chem. Phys. Lett. 1994, 226, 420-426.

(79) Maroulis, G. Electric Properties of Carbon Tetrafluoride. Chem. Phys. Lett. 1996, 259, 654-660.

(80) Maroulis, G. On the Accurate Theoretical Determination of the Static Hyperpolarizability of Trans-Butadiene. J.Chem. Phys. 1999, 111, 583-591.

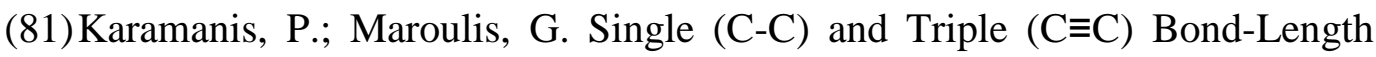
Dependence of the Static Electric Polarizability and Hyperpolarizability of H-C $\equiv \mathrm{C}-\mathrm{C}$ इC-H. Chem. Phys. Lett. 2003, 376, 403-410.

(82) Garcia-Borràs, M.; Solà, M.; Luis, J. M.; Kirtman, B. Electronic and Vibrational Nonlinear Optical Properties of Five Representative Electrides. J. Chem. Theory Comput. 2012, 8, 2688-2697.

(83) Nakano, M.; Kishi, R.; Nitta, T.; Kubo, T.; Nakasuji, K.; Kamada, K.; Ohta, K.; Champagne, B.; Botek, E.; Yamaguchi, K. Second Hyperpolarizability $(\gamma)$ of Singlet Diradical System: Dependence of $\gamma$ on the Diradical Character. J. Phys. Chem. A 2005, 109, 885-891.

(84)Møller, C.; Plesset, M. The Electron Correlation Correction to the Resulting Rhf Wavefunction Was Performed with the MP4SDTQ $\left(F_{c}\right)$ Approximation Phys. Phys. Rev. 1934, 46, 618.

(85)Head-Gordon, M.; Head-Gordon, T. Analytic MP2 Frequencies without Fifth-Order Storage. Theory and Application to Bifurcated Hydrogen Bonds in the Water Hexamer. Chem. Phys. Lett. 1994, 220, 122-128.

(86)Bishop, D. M.; Hasan, M.; Kirtman, B. A Simple Method for Determining Approximate Static and Dynamic Vibrational Hyperpolarizabilities. J. Chem. Phys. 1995, 103, 4157-4159.

(87)Luis, J. M.; Martí, J.; Duran, M.; Andrés, J. L.; Kirtman, B. Nuclear Relaxation Contribution to Static and Dynamic (Infinite Frequency Approximation) Nonlinear Optical Properties by Means of Electrical Property Expansions: 35 / 38 
Application to $\mathrm{HF}, \mathrm{CH}_{4}, \mathrm{CF}_{4}$, and $\mathrm{SF}_{6}$. J. Chem. Phys. 1998, 108, 4123-4130.

(88)Frisch, M. J.; Trucks, G. W.; Schlegel, H. B.; Scuseria, G. E.; Robb, M. A.; Cheeseman, J. R.; Scalmani, G.; Barone, V.; Mennucci, B.; Petersson, G. A.; et al. GAUSSIAN 09, Revision D.01, Gaussian, Inc., Wallingford CT, 2013.

(89)Dennington, R.; Keith, T.; Millam, J. GaussView, version 5; Semichem Inc.: Shawnee Mission, KS, 2009.

(90)Chen, Z.; Neukermans, S.; Wang, X.; Janssens, E.; Zhou, Z.; Silverans, R. E.; King, R. B.; Schleyer, P. v. R.; Lievens, P. To Achieve Stable Spherical Clusters: General Principles and Experimental Confirmations. J. Am. Chem. Soc. 2006, 128, 12829-12834.

(91)Sun, W. M.; Wu, D.; Li, Y.; Liu, J. Y.; He, H. M.; Li, Z. R. A Theoretical Study on Novel Alkaline Earth-Based Excess Electron Compounds: Unique Alkalides with Considerable Nonlinear Optical Responses. Phys. Chem. Chem. Phys. 2015, 17, 4524-4532.

(92)Zhong, R.-L.; Xu, H.-L.; Muhammad, S.; Zhang, J.; Su, Z.-M. The Stability and Nonlinear Optical Properties: Encapsulation of an Excess Electron Compound Licnli within Boron Nitride Nanotubes. J. Mater. Chem. 2012, 22, 2196-2202.

(93)Wang, J.-J.; Zhou, Z.-J.; Bai, Y.; He, H.-M.; Wu, D.; Li, Y.; Li, Z.-R.; Zhang, H.-X. A New Strategy for Simultaneously Enhancing Nonlinear Optical Response and Electron Stability in Novel Cup-Saucer ${ }^{+}$-Cage $^{-}$-Shaped Sandwich Electride Molecules with an Excess Electron Protected inside the Cage. Dalton Trans. 2015, 44, 4207-4214.

(94)Zhou, Z.-J.; Li, H.; Huang, X.-R.; Wu, Z.-J.; Ma, F.; Li, Z.-R. The Structure and Large Nonlinear Optical Properties of a Novel Octupolar Electride Li@36 Adz. Comput. Theor. Chem. 2013, 1023, 99-103.

(95)Liu, Z.-B.; Li, Y.-C.; Wang, J.-J.; Bai, Y.; Wu, D.; Li, Z.-R. Effects of the Cage Unit Size and Number of Cage Units as Well as Bridge Unit on the Second Order Nonlinear Optical Response in Multicage Electride Molecules. J. Phys. Chem. A 2013, 117, 6678-6686. 
(96)Lips, F.; Hołyńska, M.; Clérac, R.; Linne, U.; Schellenberg, I.; Pöttgen, R.; Weigend, F.; Dehnen, S. Doped Semimetal Clusters: Ternary, Intermetalloid Anions $\left[\mathrm{Ln} @ \mathrm{Sn}_{7} \mathrm{Bi}_{7}\right]^{4-}$ and $\left[\mathrm{Ln} @ \mathrm{Sn}_{4} \mathrm{Bi}_{9}\right]^{4-}(\mathrm{Ln}=\mathrm{La}, \mathrm{Ce})$ with Adjustable Magnetic Properties. J. Am. Chem. Soc. 2012, 134, 1181-1191.

(97)Nakano, M.; Champagne, B. Theoretical Design of Open-Shell Singlet Molecular Systems for Nonlinear Optics. J. Phys. Chem. Lett. 2015, 6, 3236-3256.

(98)Oudar, J. d. Optical Nonlinearities of Conjugated Molecules. Stilbene Derivatives and Highly Polar Aromatic Compounds. J. Chem. Phys. 1977, 67, 446-457.

(99)Kanis, D. R.; Ratner, M. A.; Marks, T. J. Design and Construction of Molecular Assemblies with Large Second-Order Optical Nonlinearities. Quantum Chemical Aspects. Chem. Rev. 1994, 94, 195-242.

(100)Torrent-Sucarrat, M.; Anglada, J. M.; Luis, J. M. Evaluation of the Nonlinear Optical Properties for Annulenes with HüCkel and MöBius Topologies. $J$. Chem. Theory Comput. 2011, 7, 3935-3943. 
Table of Contents Graphic

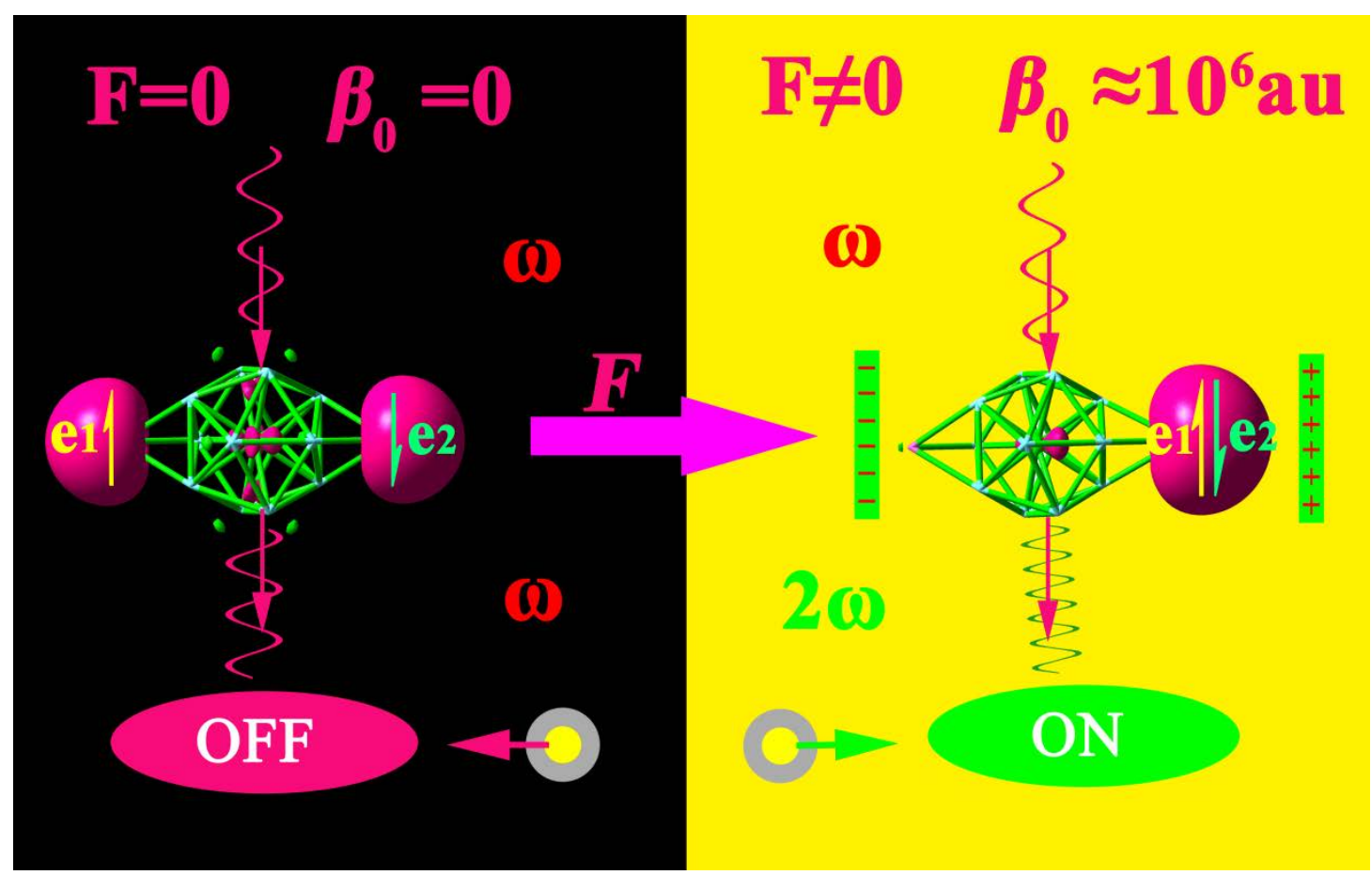

In the all-metal electride NLO switch molecules, an excess electron is driven by an external electric field from one end of the molecule to the other end, which brings dramatic $\beta_{0}$ contrast from 0 (off form) to $10^{6}$ au (on form). 